\title{
A Qualidade Em Serviços No Ambiente Organizacional
}

\section{Quality In Services In The Organizational Environment}

\author{
Andrea de Morais Miguel ${ }^{1}$, Bruna Ferreira da Silva², Jaqueline Moreira Alves Dino³, \\ Dr. João Carlos Lopes Fernandes ${ }^{4}$, Luana Morais Soares ${ }^{5}$, Dra. Mônica Maria \\ Martins de Souza ${ }^{6}$, Priscila Maria de Carvalho ${ }^{7}$, Rafaela Moreira Alves Dino Brito ${ }^{8}$
}

\begin{abstract}
1 Andrea de Morais Miguel é Administradora pelas Faculdades Campos Salles - FICS
2 Bruna Ferreira da Silva é Administradora pelas Faculdades Campos Salles - FICS

3 Jaqueline Moreira Alves Dino é Administradora pelas Faculdades Campos Salles - FICS

4.João Carlos Lopes Fernandes é bacharel em Ciências da Computação, Mestre em Engenharia de Computação e Doutor em Engenharia Biomédica na área de Tecnologias Computacionais. Coordenador do curso Análise e Desenvolvimento de Sistemas da Faculdade de Tecnologia de São Caetano do Sul, professor associado do Instituto Mauá de Tecnologia, professor e autor da pós-graduação da Unyleya, pesquisador da Faculdade ENIAC.

5 Luana Morais Soares é Administradora pelas Faculdades Campos Salles - FICS

6.Mônica Maria Martins de Souza é Psicóloga Doutora em Comunicação e Semiótica, Mestre em Administração, Especialista em RH, Docência e Tecnologia educacional. Professora de Pós-graduação do Mackenzie, UNIP, ENIAC. Coordenadora e organizadora de seminários e Editora de Anais e revista acadêmica da Campos Salles e ENIAC.

7.Priscila Maria de Carvalho é Administradora pelas Faculdades Campos Salles - FICS

8. Rafaela Moreira Alves Dino Brito é Administradora pelas Faculdades Campos Salles - FICS
\end{abstract}

\section{Resumo}

Esta pesquisa tem como objetivo explanar sobre a qualidade no ambiente organizacional, no intuito de demonstrar a importância da satisfação e motivação dos seus colaboradores, pois estes são peças chave para a imagem da organização. Um colaborador motivado desempenha sua função atingindo o alto nível de satisfação de seu cliente, gerando uma imagem positiva. Um dos fatores que interfere na motivação dos colaboradores é a cultura adotada pela organização que não consegue agradar a todos, porém, é imposta de forma que todos os indivíduos adéquam-se e hajam de acordo com a política da organização influenciando na tomada de decisões, regras e procedimentos. O clima organizacional é consequência e resultado da cultura, que pode ser percebido por meio do comportamento de seus colaboradores. Caso o ambiente esteja desagradável poderá gerar conflitos que, sendo bem administrados pela empresa, podem atuar de forma construtiva, porém, quando o conflito é mal administrado, ou seja, quando os gestores os consideram irrelevantes, faz com que o ambiente de trabalho atue de forma destrutiva para os funcionários. Para diminuir o conflito é necessário a motivação e o trabalho em equipe, a união das pessoas tem a possibilidade de atingir resultados positivos.

Palavras-chaves: Qualidade, Comportamento, Clima organizacional, Motivação e Satisfação. 


\begin{abstract}
This research has the objective to explain about the quality in the organizational environment, to demonstrate the importance of employees' satisfaction and motivation, because these affect the organization's image. A motivated employee executes his function performing a high level of satisfaction of the client, generating a positive image. One of the factors that interfere with the motivation of employees is the culture adopted by the organization that cannot gratify everyone, however, it is imposed so that all individuals adapt and act according to the organization's political having an affect on decisions, rules and procedures. The organizational environment is consequence and result of the culture, which can be realized by the behavior of their employees. If the environment is distasteful may generate conflicts, having an appropriate management by the company, they can act constructively, though, when conflict is badly managed, in other words, when managers consider them irrelevant, makes the environment works negatively. To reduce the conflict is necessary motivation and teamwork, so that people's union have the possibility to reach positive results.
\end{abstract}

Key words: Quality, Behavior, Organization Environment, Motivation and Satisfaction.

\section{Introdução}

A presente pesquisa procura estabelecer uma reflexão sobre a satisfação dos colaboradores com o ambiente da organização. O objetivo é compreender de que forma se dá a qualidade no ambiente organizacional, com o intuito de demonstrar a importância da satisfação e motivação dos colaboradores, como peças chave para fortalecer a imagem da organização. As pessoas são essenciais na empresa e quando insatisfeitas com a organização podem gerar um impacto negativo para o cliente.

O que justifica a elaboração da pesquisa é detectar como a cultura da organização promove pontos positivos e/ou negativos para os funcionários, os quais geram conflitos que podem causar progressos ou danos ao ambiente de trabalho.
As estratégias de investigação adotadas foram pesquisas bibliográficas, eletrônicas e pesquisas de campo com observação online. Foram entrevistadas 06 empresas do ramo de comercio e varejo, na região da Lapa. Houve contato direto com colaboradores e clientes mensurando e analisando a motivação dos funcionários e a sua interferência no atendimento e resultados da empresa.

Um funcionário não satisfeito com a cultura praticada pela organização, pode afetar ou influenciar todo setor, pois a cultura da empresa não agrada a todos, por que o que pode ser bom para um é ruim para outro, gerando o conflito organizacional. A empresa sente o impacto, pois onde existe o conflito os colaboradores mostram através do seu serviço, gerando uma percepção totalmente negativa com o cliente. Por isso a empresa deve evitar ao máximo que o conflito se espalhe, colocando sempre como evidência a visão de como o funcionário se sente dentro da organização os deixando expor suas opiniões e sugestões para melhoramento da empresa. 
Nesse contexto os funcionários são o foco das organizações, pois insatisfeitos ou desmotivados com a empresa irão demonstrar para o cliente com o seu serviço ou atendimento prestado. Segundo Ducker (1999, p.107) “As pessoas determinam a capacidade de desempenho da organização. Nenhuma organização pode ir melhor que as pessoas que tem".

A Qualidade no Ambiente Organizacional é muito importante no mundo atual, pois é por meio da cultura da empresa (missão, visão e valores) que é estabelecido um clima agradável para os funcionários que nela atuam. E se esse ambiente estiver desagradável, podem surgir os conflitos que dependendo da intensidade pode trazer consequências graves para a organização.

Por meio dessa pesquisa vamos mostrar como as empresas passaram a perceber que o funcionário não era uma função mecânica de trabalho, e como passaram a entender que o trabalhador também tinha o direito de opinar e entender melhor o seu trabalho.

No entanto muitos funcionários atualmente não se sentem motivados com a organização, por esse motivo será relatado sobre as necessidades humanas e mostrar também como motivar as equipes de trabalho. Colocando sempre como evidência o bem estar do ser humano no seu ambiente de trabalho. Para que os colaboradores se sintam à vontade com a organização, é necessário existir um trabalho em equipe, fazendo com que todos trabalhem juntos para obter um resultado positivo dentro da organização.

\section{Origem Da Cultura E Dos Valores Organizacionais}

Atualmente a maioria das empresas busca satisfazer e, criar métodos para que os funcionários trabalhem sempre motivados, fazendo com que o resultado final do atendimento prestado para os clientes seja positivo.

Os empresários de hoje passaram a entender que, a empresa só consegue atuar com eficácia por meio das pessoas que nela atuam. Uma pessoa insatisfeita com a organização ou um simples gerente que não valoriza a sua equipe, pode afetar toda organização de forma negativa.

\footnotetext{
As empresas são constituídas por pessoas. Da mesma forma que a física estuda o átomo como sua unidade fundamental, também a teoria administrativa focaliza o indivíduo como sua base de análise. A motivação, a liderança e a comunicação são os principais meios de dirigir as pessoas dentro das empresas (CHIAVENATO, 2007, p. 296).
}

A cultura da empresa e os seus valores também podem afetar as pessoas, pois a organização não consegue agradar a todos, uns podem ficar satisfeitos e outros não. Mas hoje as pessoas são bem mais valorizadas que antigamente, a maioria dos líderes buscam saber, 
as necessidades dos seus colaboradores, para manter um ambiente agradável para todos.

Antigamente as pessoas no trabalho eram vistas como um instrumento de produção, os gerentes não ligavam para os aspectos psicológicos e para as necessidades dos funcionários. Eles não serviam para pensar só para executar a operação, com determinado intervalo de tempo.

Durante décadas a gestão de pessoas tem sido compreendida como uma função mecânica, ou seja, a princípio os colaboradores eram vistos como ferramenta de produção para exercer suas determinadas funções.

1.1 Reflexo da cultura no clima organizacional

O Clima Organizacional é consequência e resultado da Cultura organizacional. A palavra clima origina-se do grego klimae significa tendência ou inclinação. O Clima não é algo que se pode tocar, e é percebido nas organizações com o comportamento de seus colaboradores conforme Campello:

Está vinculado á motivação, lealdade e a identificação da empresa, à colaboração entre pessoas, ao interesse no trabalho, à facilidade das comunicações internas, aos relacionamentos entre as pessoas, aos sentimentos e emoções, à integração da equipe e outras variáveis (CAMPELLO (2011, p. 282).
Nas organizações o clima reflete na qualidade do ambiente e desempenho de tarefas, é percebido por todos, como já dito é fortemente influenciado pela cultura. O maior desafio das organizações é identificar o nível de satisfação dos colaboradores, os acertos, erros, frustrações, e ansiedades no ambiente interno o qual é chamado de clima, são atitudes primordiais numa organização, para conquistar resultados positivos. Muitas vezes o clima é influenciado por sentimentos pessoais deixando de lado o profissionalismo. Mostrar que o colaborador tem um valor para a organização e digno de atenção, ajuda na dedicação de um melhor atendimento e no serviço prestado.

Em uma admissão, o candidato deixa de ser livre e não mais se comporta como lhe convém, passa a seguir as regras impostas pela organização passando a assumir a identidade da empresa, para que haja esta integração os colaboradores devem aceitar as políticas, normas e valores. Uma boa interação entre líderes e subordinados gera um clima saudável, contribuindo assim para motivação e compartilhando conhecimentos além de confiança que eleva a satisfação em realizar todas suas atividades, elevando a qualidade de vida no ambiente organizacional, influenciado pelo estado motivacional e por ele influenciado. A comunicação é um forte aliado para um ambiente agradável nas organizações, trata-se de transmissão de mensagens que está ligada ao emocional e intelectual, pode ser feita pela: escrita, audição, visão, fala. 
A falha na comunicação pode resultar em conflitos gerando um clima desagradável nas organizações e entre os indivíduos conforme esquema da figura 3.

\subsection{Consequências do Clima em relação à cultura}

As consequências do clima organizacional estão ligadas a cultura, política e valores das organizações. Para que se tenha qualidade de vida no ambiente de trabalho, é necessário que todos aceitem a cultura imposta pela organização e que tenham uma boa interação entre líderes e subordinados. A não aceitação da cultura ou política da empresa pode gerar conflitos, fazendo com que seus colaboradores trabalhem desmotivados, desta forma gerando prejuízo para empresa.

Como já visto em toda pesquisa de campo anexa a este trabalho, além da aceitação da cultura, a motivação do líder gera motivação no colaborador, fazendo com que este trabalhe com qualidade e satisfeito.

\section{Pesquisa De Campo}

As pesquisas foram realizadas nas lojas (Pontal, Mundial, Gabriela, Alegria, A colossal e Shoebiz), localizadas na região da Lapa (Zona Oeste de São Paulo), que atendem ao Mercado de comercio e varejo. Os clientes "abordados" nas lojas, responderam um questionário contendo 6 (seis) questões e os funcionários 28 (vinte e oito). No total obteve-se 90 questionários respondidos por completo e, a pesquisa foi feita entre os meses de Julho e Agosto do ano de 2013. Após esse processo foi feita a tabulação das questões com a finalidade de obter resultados de satisfação e/ou insatisfação para com os serviços prestados pelas organizações.

\subsection{Análise da Pesquisa}

O objetivo da pesquisa é mostrar que, a qualidade no ambiente organizacional interfere no atendimento realizado aos clientes. Esta pesquisa mostra que fatores como a motivação, e um bom relacionamento entre colaboradores e líderes refletem na satisfação dos clientes.

Resultado da Pesquisa de Campo Funcionários

1. Idade

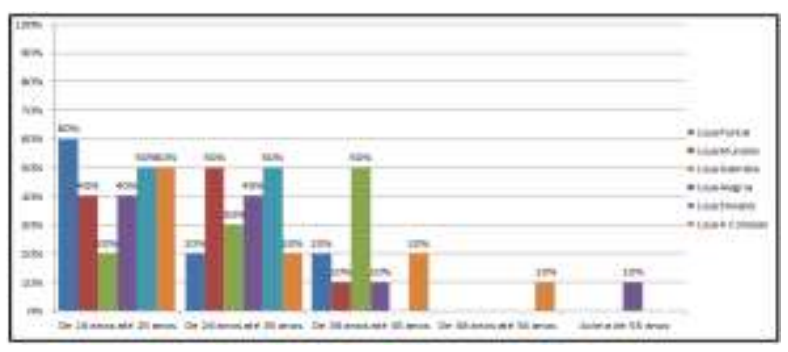

Loja Pontal: apresenta índice de 60\% de colaboradores, com idade entre 16 anos até 25 anos, $20 \%$ de 26 anos até 35 anos e $20 \%$ de 36 anos até 45 anos.

Loja Mundial: apresenta índice de 40\% dos colaboradores com idade entre 16 anos até 
25 anos, $50 \%$ de 26 anos até 35 anos e 10\% de 36 anos até 45 anos.

Loja Gabriela: apresenta índice de 50\% dos colaboradores com idade entre 36 anos até 45 anos, 20\% de 16 anos até 25 anos e 30\% de 26 anos até 35 anos.

Loja Alegria: apresenta índice de 40\% dos colaboradores com idade entre 16 anos até 25 anos, $40 \%$ de 26 anos até 35 anos, 10\% de 36 anos até 45 anos e 10\% Acima de 55 anos.

Loja Shoebiz: apresenta índice de 50\% dos colaboradores com idade entre 26 anos até 35 anos, 50\% de 16 anos até 25 anos.

Loja Gabriela: apresenta índice de 50\% dos colaboradores com idade entre 16 anos até 25 anos, 20\% de 26 anos até 35 anos, 20\% de 36 anos até 45 anos e 10\% de 45 até 55 anos.

Os resultados mostram que a variação da faixa etária para cada entrevistado é relevante. Nas Lojas Pontal 60\%, Mundial 40\% e Gabriela $20 \%$ dos seus colaboradores tem até 25 anos, percebe-se que a procura de profissionais nesta área é voltada aos jovens, devido a facilidade, agilidade e desenvoltura no atendimento.

2. Sexo

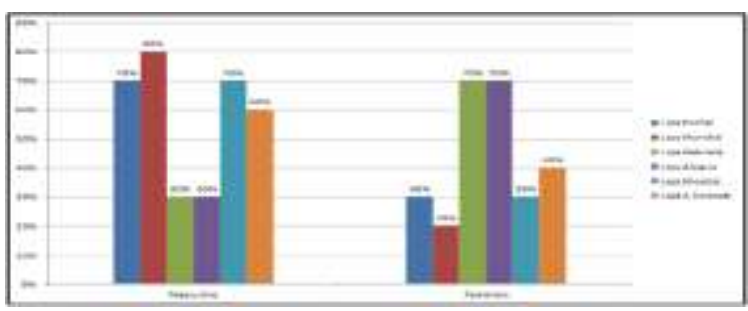

Loja Pontal: apresenta um índice de 50\% dos colaboradores do sexo Masculino e $50 \%$ do sexo feminino.
Loja Mundial: apresenta um índice de $80 \%$ dos colaboradores do sexo Masculino e $20 \%$ do sexo feminino.

Loja Gabriela: apresenta um índice de $30 \%$ dos colaboradores do sexo Masculino e $70 \%$ do sexo feminino.

Loja Alegria: apresenta um índice de $30 \%$ dos colaboradores do sexo Masculino e $70 \%$ do sexo feminino.

Loja Shoebiz: apresenta um índice de $70 \%$ dos colaboradores do sexo Masculino e $30 \%$ do sexo feminino.

Loja Colossal: apresenta um índice de $60 \%$ dos colaboradores do sexo Masculino e $40 \%$ do sexo feminino. Conforme pesquisa, podemos observar que não há restrições de sexo para exercer a atividade de atendimento ao publico, as seis empresas entrevistadas não tem preferência em homem ou mulher, mas é possível observarmos que na loja Mundial o índice maior de funcionários são do sexo masculino com $80 \%$ na amostra.

3. Escolaridade

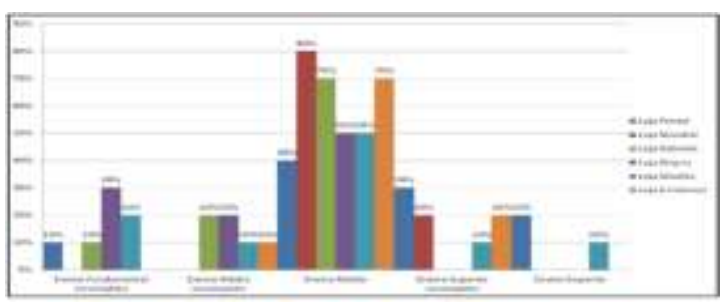

Loja Pontal: apresenta um índice de 10\% dos colaboradores que não concluiram o Ensino Fundamental, 40\% possuem o Ensino Médio Completo, $30 \%$ não concluiram o Ensino Superior e 20\% possuem o Ensino Superior completo. 
Loja Mundial: apresenta um índice de $80 \%$ dos colaboradores que concluíram o Ensino Médio e 20\% possuem Ensino Superior incompleto.

Loja Gabriela: apresenta um índice de $10 \%$ dos colaboradores que concluíram o Ensino Fundamental, 20\% não concluiram o Ensino Médio e 70\% possuem o Ensino Médio Completo.

Loja Alegria: apresenta um índice de $30 \%$ dos colaboradores que concluíram o Ensino Fundamental, 20\% não concluiram o Ensino Médio e 50\% possuem o Ensino Médio Completo.

Loja Shoebiz: apresenta um índice de $20 \%$ dos colaboradores que concluíram o Ensino Fundamental, 10\% não concluíram o Ensino Médio, 50\% possuem o Ensino Médio Completo, $10 \%$ não concluíram o Ensino Superior e 10\% possuem Ensino Superior Completo.

Loja A Colossal: apresenta um índice de 10\% dos colaboradores que concluíram o Ensino Médio, 70\% concluíram o Ensino Médio e 20\% possuem o Ensino Superior Incompleto.

Com os resultados dos gráficos acima observamos, que essas organizações não exigem nível de escolaridade para contratação de profissionais na área de vendas.
4. Há quanto tempo trabalha na empresa?

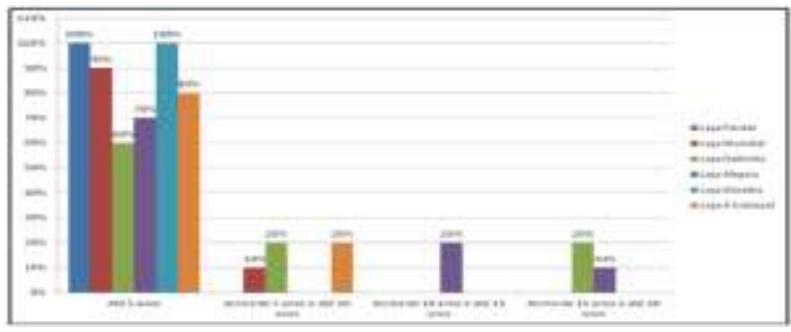

Na loja Pontal 100\% dos colaboradores exercem suas funções à aproximadamente 5 anos.

Na loja Mundial 90\% dos colaboradores exercem suas funções à aproximadamente 5 anos e $10 \%$ entre 5 e 10 anos.

$\mathrm{Na}$ loja Gabriela 60\% dos colaboradores exercem suas funções à aproximadamente 5 anos, $20 \%$ entre 5 e 10 anos e $20 \%$ estão de 15 à 20 anos.

$\mathrm{Na}$ loja Alegria 70\% dos colaboradores exercem suas funções à aproximadamente 5 anos, 20\% entre 10 à 15 anos e 10\% estão de 15 à 20 anos.

Na loja Pontal 100\% dos colaboradores exercem suas funções à aproximadamente 5 anos.

$\mathrm{Na}$ loja A Colossal $80 \%$ dos colaboradores exercem suas funções à aproximadamente 5 anos e $20 \%$ entre 5 à 10 anos.

Devido à falta de oportunidade (crescimento), podemos identificar que o índice de estabilidade nas organizações é baixo, apesar da qualidade no ambiente, esses funcionários procuram oportunidades em outras organizações. 
1. O que mais o motiva a trabalhar nesta empresa?

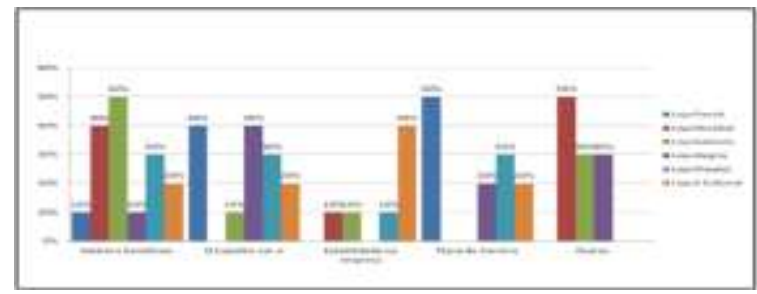

Na loja Pontal 10\% dos colaboradores estão motivados por salário e benefícios, $40 \%$ pela função que exerce e $50 \%$ pelo plano de carreira.

Na loja Mundial 40\% dos colaboradores estão motivados por salário e benefícios, 10\% pela estabilidade e $50 \%$ por outros motivos, como por exemplo: a carga horária.

$\mathrm{Na}$ loja Alegria 10\% dos colaboradores estão motivados por salário e benefícios, $40 \%$ pela função que exerce, $20 \%$ devido ao plano de carreira e $30 \%$ por outros motivos, não informado.

Na loja Shoebiz 30\% dos colaboradores estão motivados por salário e benefícios, 30\% pela função que exerce, $10 \%$ pela estabilidade e $30 \%$ pelo plano de carreira.

$\mathrm{Na}$ loja A Colossal 20\% dos colaboradores estão motivados por salário e benefícios, $20 \%$ pela função que exerce, $40 \%$ pela estabilidade e $20 \%$ pelo plano de carreira.

Os gráficos acima apresentam índices diversos para motivação, como salários e benefícios, carga horária, entre outros. Nota-se que o ambiente de trabalho também contribui com a motivação dos colaboradores. Qual seu nível de satisfação em relação ao seu salário e benefícios?

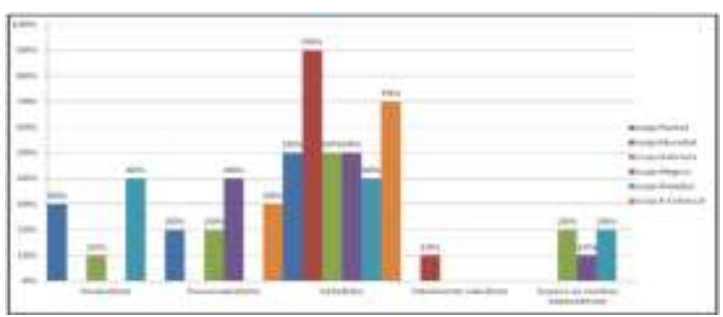

Na loja Pontal 30\% dos colaboradores estão Insatisfeitos com salário e beneficio 20\% pouco satisfeito e $50 \%$ satisfeito.

Na loja Mundial 90\% dos colaboradores estão satisfeitos com salário e beneficio $10 \%$ totalmente satisfeito.

Na loja Gabriela 10\% dos colaboradores estão Insatisfeitos com salário e beneficio, 20\% pouco satisfeito, $50 \%$ satisfeito e $20 \%$ acima da expectativa.

$\mathrm{Na}$ loja Alegria 40\% dos colaboradores estão pouco satisfeitos com salário e beneficio, $50 \%$ satisfeito e $10 \%$ acima da expectativa.

Na loja Shoebiz 40\% dos colaboradores estão Insatisfeitos com salário e beneficio, 40\% satisfeito e $20 \%$ acima da expectativa.

$\mathrm{Na}$ loja A Colossal 30\% dos colaboradores estão pouco satisfeitos com salário e beneficio e 70\% satisfeito.

$O$ índice de satisfação em relação a salários e benefícios é considerado um efeito de motivação, conforme já apresentado na questão $\mathrm{n}^{\mathrm{o}}$ 5. O que mais o motiva a trabalhar nesta empresa? 
2. Os funcionários são

tratados com respeito, independente de seus cargos?

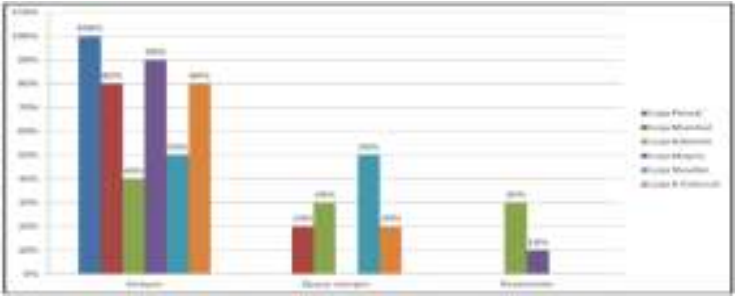

Na loja Pontal 100\% dos funcionários são tratados com respeito sempre, independente do cargo.

$\mathrm{Na}$ loja Mundial 80\% dos funcionários são tratados com respeito sempre e $20 \%$ quase sempre independente do cargo.

$\mathrm{Na}$ loja Gabriela 40\% dos funcionários são tratados com respeito sempre, $30 \%$ quase sempre e $30 \%$ raramente independente do cargo.

$\mathrm{Na}$ loja Alegria 90\% dos funcionários são tratados com respeito sempre e $10 \%$ raramente independente do cargo.

Na loja Shoebiz 50\% dos funcionários são tratados com respeito sempre e 50\% quase sempre independente do cargo.

Na loja A Colossal 80\% dos funcionários são tratados com respeito sempre e $20 \%$ quase sempre independente do cargo.

Analisando os resultados, observamos que as lojas onde o índice respeito os funcionários da loja Pontal estão 100\% satisfeitos com o tratamento recebido em sua organização, com isso apresentam bons resultados na execução de suas tarefas. Nas demais lojas tem um baixo índice de respeito, os entrevistados que são raramente tratados com respeito tendem a não apresentar resultados positivos para organização.

3. Você é elogiado quando executa um bom trabalho?

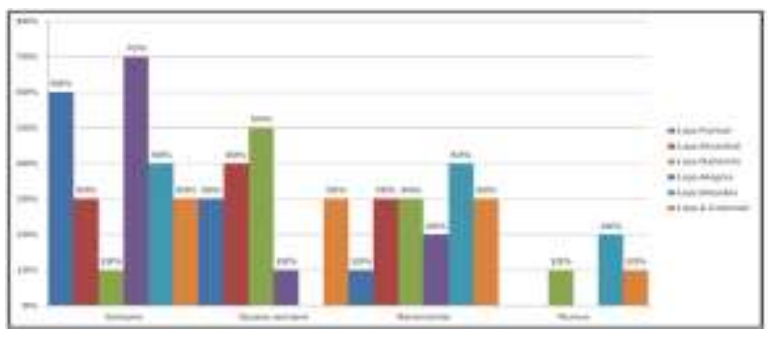

$\mathrm{Na}$ loja Pontal 60\% dos funcionários sempre recebem elogios quando executam bem suas tarefas, $30 \%$ quase sempre e $10 \%$ raramente.

$\mathrm{Na}$ loja Mundial 30\% dos funcionários sempre recebem elogios quando executam bem suas tarefas, $40 \%$ quase sempre e $30 \%$ raramente.

$\mathrm{Na}$ loja Gabriela 10\% dos funcionários sempre recebem elogios quando executam bem suas tarefas, $50 \%$ quase sempre, $30 \%$ raramente e $10 \%$ nunca.

$\mathrm{Na}$ loja Alegria 70\% dos funcionários sempre recebem elogios quando executam bem suas tarefas, $10 \%$ quase sempre e $20 \%$ raramente.

$\mathrm{Na}$ loja Shoebiz 40\% dos funcionários sempre recebem elogios quando executam bem suas tarefas, $40 \%$ raramente e $20 \%$ nunca.

Na loja A Colossal 30\% dos funcionários sempre recebem elogios quando executam bem suas tarefas, 30\% quase sempre, 30\% raramente e $10 \%$ nunca.

Analisando os resultados, a frequência de elogios recebidos na loja Pontal é 60\%, 
mostrando que os funcionários são incentivados a executar um bom trabalho. Nas demais lojas, funcionários são raramente elogiados, o percentual é de $10 \%$ podendo gerar a desmotivação e a falta de desempenho nestes

4. O seu líder é participativo (faz reuniões, abre discussões, ouve e dá espaço aos funcionários para participarem dos processos de tomada de decisões, de maneira

$\mathrm{Na}$ loja Pontal $50 \%$ dos funcionários alegam que seu líder é sempre participativo, 40\% apontam que quase sempre há participação do líder e 10\% responderam que seu líder raramente é participativo.

Na loja Mundial 80\% dos funcionários alegam que seu líder é sempre participativo, 10\% apontam que quase sempre há participação do líder e 10\% responderam que seu líder raramente é participativo.

Na loja Gabriela 10\% dos funcionários alegam que seu líder é sempre participativo, 10\% apontam que quase sempre há participação do líder ,60\% responderam que seu líder raramente é participativo e $20 \%$ responderam que o líder nunca é participativo.

Na loja Alegria 70\% dos funcionários alegam que seu líder é sempre participativo, 20\% apontam que quase sempre há participação do líder e 10\% responderam que o líder nunca é participativo.

$\mathrm{Na}$ loja Shoebiz 30\% dos funcionários alegam que seu líder é sempre participativo, 20\% colaboradores. O reconhecimento de um trabalho bem elaborado ou meta alcançada é uma das ferramentas motivacionais, quando um colaborador que é elogiado aumenta sua autoestima.

democrática)?

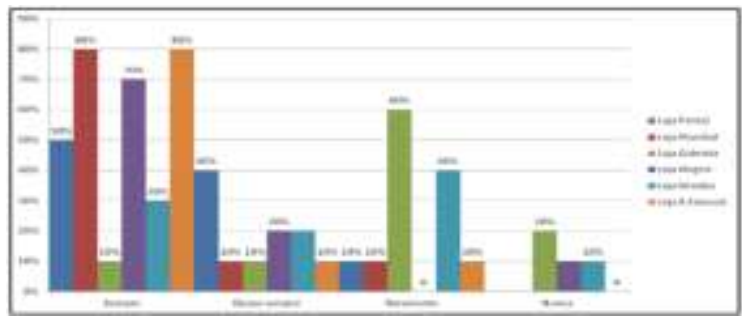

apontam que quase sempre há participação do líder ,40\% responderam que seu líder raramente é participativo e $10 \%$ responderam que o líder nunca é participativo.

Na loja A Colossal 80\% dos funcionários alegam que seu líder é sempre participativo, 10\% apontam que quase sempre há participação do líder e 10\% responderam que seu líder raramente é participativo.

Com os resultados obtidos na pesquisa, observamos que há na loja Pontal com 50\% e loja Mundial com $80 \%$, os funcionários identificam seus lideres como participativos em seu ambiente de trabalho, já na loja Gabriela $60 \%$ das pessoas entrevistadas identificaram que seus lideres raramente são participativos.

5. O seu líder é motivador?

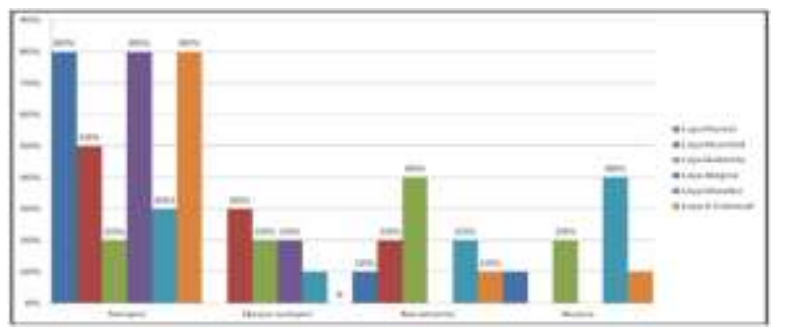


Na loja Pontal 80\% dos funcionários veem o líder como motivador, $10 \%$ aponta que raramente o líder é motivador e 10\% alegam que o líder nunca é motivador.

$\mathrm{Na}$ loja Mundial 50\% dos funcionários veem o líder como motivador, $30 \%$ aponta que quase sempre o líder é motivador e 20\% alegam que raramente o lider é motivador.

Na loja Gabriela 20\% dos funcionários veem o líder como motivador, $20 \%$ aponta que quase sempre o líder é motivador, 40\% alegam que raramente o líder é motivado e $20 \%$ responderam que o líder nunca é motivador.

$\mathrm{Na}$ loja Alegria 80\% dos funcionários veem o líder como motivador e $20 \%$ aponta que quase sempre o líder é motivador.

Na loja Shoebiz 30\% dos funcionários veem o líder como motivador, $10 \%$ aponta que quase sempre o líder é motivador, 20\% alegam que o líder raramente é motivador e 40\% responderam que o líder nunca é motivador.

$\mathrm{Na}$ loja A Colossal 80\% dos funcionários veem o líder como motivador, $10 \%$ aponta que raramente o líder é motivador e 10\% responderam que o líder nunca é motivador.

11. As orientações que você recebe sobre o seu trabalho são claras e objetivas?

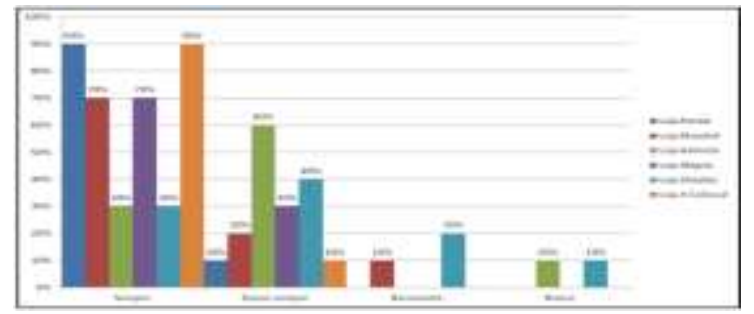

$\mathrm{Na}$ loja Pontal 90\% dos funcionários alegam que recebem sempre orientações claras e objetivas e $20 \%$ informam que quase sempre.

$\mathrm{Na}$ loja Mundial 70\% dos funcionários alegam que recebem sempre orientações claras e objetivas, $20 \%$ informam que quase sempre e $10 \%$ raramente.

Na loja Gabriela 30\% dos funcionários alegam que recebem sempre orientações claras e objetivas, $60 \%$ informam que quase sempre e $10 \%$ nunca.

$\mathrm{Na}$ loja Alegria 70\% dos funcionários alegam que sempre recebem orientações claras e objetivas e 30\% informam que quase sempre.

$\mathrm{Na}$ loja Shoebiz 30\% dos funcionários alegam que recebem orientações claras e objetivas, $40 \%$ informam que quase sempre, $20 \%$ raramente e $10 \%$ nunca.

Na loja A Colossal 90\% dos funcionários alegam que sempre recebem orientações claras e objetivas e $10 \%$ informam que quase sempre.

Os gráficos mostram que as opiniões são divididas entre as lojas pesquisadas. Nas lojas Pontal e Colossal o índice foi de $90 \%$ de orientações claras e objetivas, na loja Gabriela teve maior índice de resposta que as orientações quase sempre são claras e objetivas, devido a falhas de comunicação. 
12. Você vê possibilidade de crescimento de carreira na empresa?

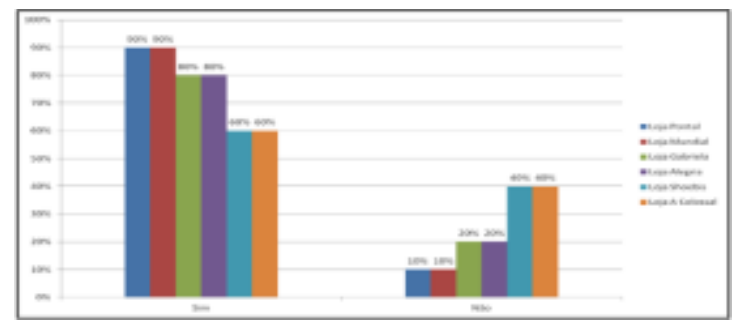

Na loja Pontal 90\% dos funcionários veem possibilidade de crescimento profissional e 10\% não veem essa possibilidade.

$\mathrm{Na}$ loja Mundial 90\% dos funcionários veem possibilidade de crescimento profissional e $10 \%$ não veem essa possibilidade.

Na loja Gabriela 80\% dos funcionários veem possibilidade de crescimento profissional e 20\% não veem essa possibilidade.

Na loja Alegria 80\% dos funcionários veem possibilidade de crescimento profissional e $20 \%$ não veem essa possibilidade.

Na loja Shoebiz 60\% dos funcionários veem possibilidade de crescimento profissional e 40\% não veem essa possibilidade.

$\mathrm{Na}$ loja A Colossal 60\% dos funcionários veem possibilidade de crescimento profissional e $40 \%$ não veem essa possibilidade.

Analisando os resultados, nota-se que a maior parte dos funcionários entrevistados veem possibilidades de plano de carreira, consequentemente eles desempenham um trabalho satisfatório para a empresa.
13. Você se sente realizado profissionalmente?

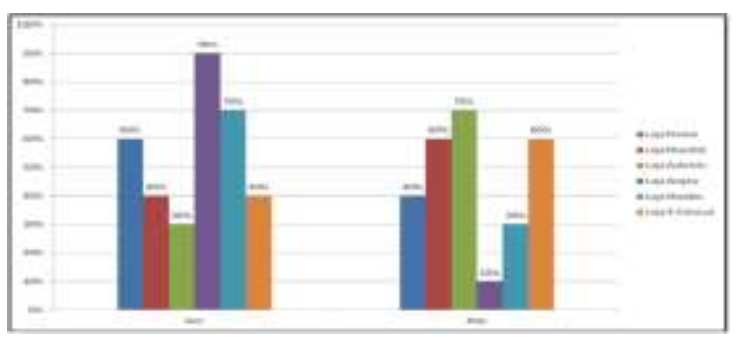

$\mathrm{Na}$ loja Pontal 60\% dos funcionários dizem se sentir realizados profissionalmente, e $40 \%$ não estão satisfeitos com a sua profissão.

$\mathrm{Na}$ loja Mundial 40\% dos funcionários dizem se sentir realizados profissionalmente, e 60\% não estão satisfeitos com a sua profissão.

Na loja Gabriela 30\% dos dizem se sentir realizados profissionalmente, e $70 \%$ não estão satisfeitos com a sua profissão.

$\mathrm{Na}$ loja Alegria 90\% dos funcionários dizem se sentir realizados profissionalmente, e $10 \%$ não estão satisfeitos com a sua profissão.

Na loja Shoebiz 70\% dos funcionários dizem se sentir realizados profissionalmente, e $30 \%$ não estão satisfeitos com a sua profissão.

Na loja A Colossal 40\% dos funcionários dizem se sentir realizados profissionalmente, e $60 \%$ não estão satisfeitos com a sua profissão.

$\mathrm{Na}$ Loja Pontal consta o maior índice de satisfação profissional, conforme gráficos anteriores esta empresa oferece plano de carreira e tem líder mais participativo. Isso mostra que líderes que participam se preocupam com o bem estar do funcionário faz com que todos se sentem realizados profissionalmente. 
14. Qual o seu nível de satisfação em relação a

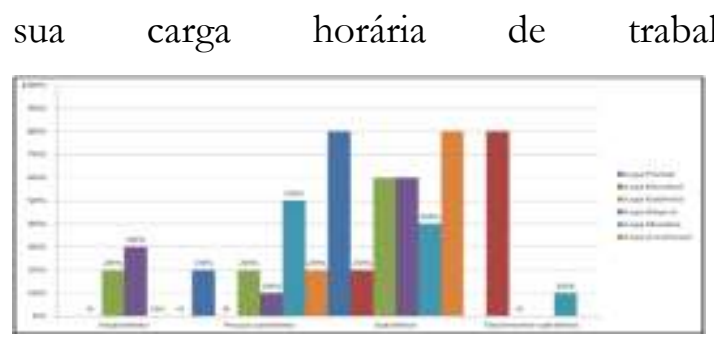

Na loja Pontal 20\% dos colaboradores estão "Pouco satisfeitos" em relação à carga horária de trabalho e $80 \%$ estão "satisfeitos".

Na loja Mundial 20\% dos colaboradores estão “satisfeitos" em relação à carga horária de trabalho e $80 \%$ estão "totalmente satisfeitos".

Na loja Gabriela 20\% dos colaboradores estão "insatisfeitos” em relação à carga horária de trabalho, 20\% estão "pouco satisfeitos e 60\% estão "satisfeitos".

Na loja Alegria 30\% dos colaboradores estão "insatisfeitos" em relação à carga horária de trabalho,10\% estão "pouco satisfeitos" e 60\% estão "satisfeitos".

Na loja Pontal 100\% dos colaboradores responderam que os gestores da empresa prezam pelo bom ambiente de trabalho.

$\mathrm{Na}$ loja Mundial 80\% dos colaboradores responderam que os gestores da empresa prezam pelo bom ambiente de trabalho e $20 \%$ não identificam esse ponto em seus gestores.

Na loja Gabriela 70\% dos colaboradores responderam que os gestores da empresa prezam pelo bom ambiente de trabalho e 30\% não identificam esse ponto em seus gestores.

Na loja Alegria 100\% dos colaboradores responderam que os gestores da empresa prezam pelo bom ambiente de trabalho.
Na loja Shoebiz 50\% dos colaboradores estão "pouco satisfeitos" em relação à carga horária de trabalho, 40\% estão "satisfeitos" e $10 \%$ estão "totalmente satisfeitos".

$\mathrm{Na}$ loja A Colossal $20 \%$ dos colaboradores estão "pouco satisfeitos" em relação à carga horária de trabalho e $80 \%$ estão "satisfeitos".

Em relação à carga horária houve um nível de satisfação positivo, a loja Mundial foi a que apresentou o nível maior de satisfação com $80 \%$ de totalmente satisfeito. Isso mostra que a carga horária da loja Mundial é flexível para que todos os funcionários fiquem satisfeitos.

15. Os gestores da empresa prezam pelo bom ambiente de trabalho?

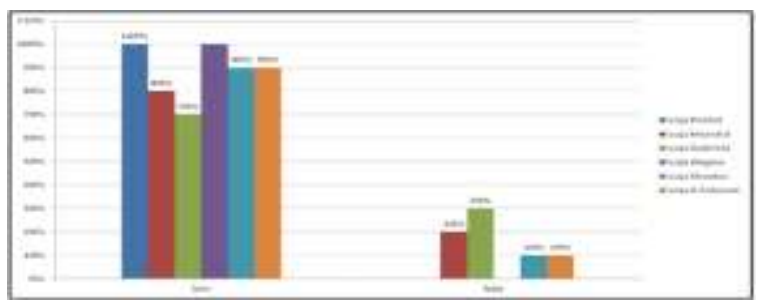

Na loja Shoebiz 90\% dos colaboradores responderam que os gestores da empresa prezam pelo bom ambiente de trabalho e 10\% não identificam esse ponto em seus gestores.

$\mathrm{Na}$ loja A Colossal $90 \%$ dos colaboradores responderam que os gestores da empresa prezam pelo bom ambiente de trabalho e $10 \%$ não identificam esse ponto em seus gestores. A pesquisa mostra que todos os gestores se preocupam com um bom ambiente de trabalho, sendo mais satisfatório com índice de $100 \%$ na loja Pontal e Alegria. 
16. Você tem autonomia para fazer

o seu trabalho da forma que

Na loja Pontal 50\% dos colaboradores classificam que a empresa "sempre", oferece a autonomia para o funcionário fazer o seu trabalho da forma que considera melhor, $40 \%$ "quase sempre" e 10\% responderam que acontece "raramente".

Na loja Mundial 90\% dos colaboradores classificam que a empresa "sempre", oferece a autonomia para o funcionário fazer o seu trabalho da forma que considera melhor e 10\% responderam que acontece "raramente".

Na loja Gabriela 50\% dos colaboradores classificam que a empresa "sempre" oferece a autonomia para o funcionário fazer o seu trabalho da forma que considera melhor, 10\% "quase sempre", 20\% "raramente" e 20\% responderam que "nunca" acontece.

Na loja Alegria 80\% dos colaboradores classificam que a empresa "sempre" oferece a autonomia para o funcionário fazer o seu trabalho da forma que considera melhor e $20 \%$ responderam que acontece "raramente".

Na loja Pontal 40\% dos colaboradores concordam que o seu gestor exerce pressão sobre seu ritmo de trabalho e 60\% discordam da existência de pressão no ritmo de trabalho.

Na loja Mundial 20\% dos colaboradores concordam que o seu gestor exerce pressão considera

melhor?

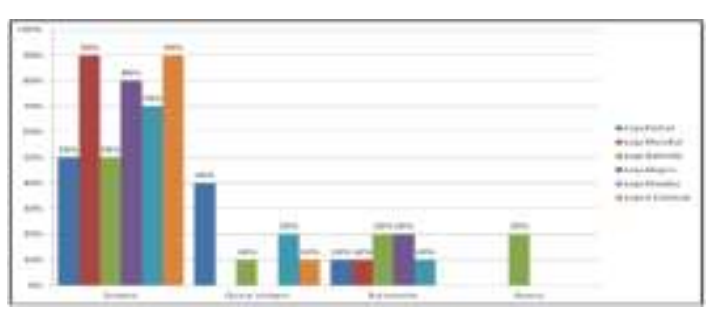

Na loja Shoebiz 70\% dos colaboradores classificam que a empresa "sempre" oferece a autonomia para o funcionário fazer o seu trabalho da forma que considera melhor, $20 \%$ "quase sempre" e 10\% responderam que acontece "raramente".

$\mathrm{Na}$ loja A Colossal $90 \%$ dos colaboradores classificam que a empresa "sempre" oferece a autonomia para o funcionário fazer o seu trabalho da forma que considera melhor e 10\% responderam que acontece "quase sempre".

Todos os entrevistados informaram que podem realizar seu trabalho de forma que julgam ser correto, mas em destaque está as lojas Mundial e Colossal com 90\%.

\section{Seu gestor exerce pressão sobre} seu ritmo de trabalho?

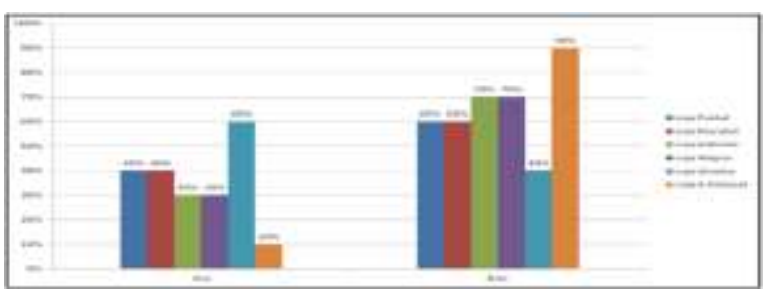

sobre seu ritmo de trabalho e $80 \%$ discordam da existência de pressão no ritmo de trabalho.

Na loja Gabriela 30\% dos colaboradores concordam que o seu gestor exerce pressão sobre seu ritmo de trabalho e $70 \%$ discordam da existência de pressão no ritmo de trabalho. 
Na loja Alegria 30\% dos colaboradores concordam que o seu gestor exerce pressão sobre seu ritmo de trabalho e $70 \%$ discordam da existência de pressão no ritmo de trabalho.

Na loja Shoebiz 60\% dos colaboradores concordam que o seu gestor exerce pressão sobre seu ritmo de trabalho e $40 \%$ discordam da existência de pressão no ritmo de trabalho.

$\mathrm{Na}$ loja A Colossal 10\% dos colaboradores concordam que o seu gestor exerce pressão sobre seu ritmo de trabalho e 90\% discordam da existência de pressão no ritmo de trabalho. Foi observado que não há pressão sobre o ritmo de trabalho por parte dos gestores, exceto na loja Shoebiz que teve um índice de 60\% afirmando sofrer pressão no ambiente de trabalho, embora o gráfico da questão 16 mostra a pergunta: "Você tem autonomia para fazer o seu trabalho da forma que considera melhor?" A resposta teve um índice significativo de $70 \%$ positivo.

18. Em sua opinião, o trabalhador motivado desempenha melhor a sua função.

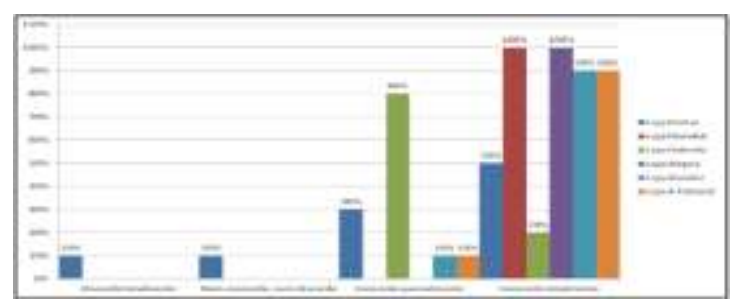

Na loja Pontal 10\% dos colaboradores "discordam totalmente" que o trabalhador motivado desempenha melhor sua função, 10\% "nem concordam e nem discordam", 30\% "concordam parcialmente" e 50\% "concordam totalmente".

$\mathrm{Na}$ loja Mundial 100\% dos colaboradores "concordam totalmente" que o trabalhador motivado desempenha melhor sua função.

Na loja Gabriela 80\% dos colaboradores "concordam parcialmente" que o trabalhador motivado desempenha melhor sua função e $20 \%$ "concordam totalmente".

Na loja Alegria 100\% dos colaboradores "concordam totalmente" que o trabalhador motivado desempenha melhor sua função.

Na loja Shoebiz 10\% dos colaboradores "discordam parcialmente" que o trabalhador motivado desempenha melhor sua função e $90 \%$ "concordam totalmente".

$\mathrm{Na}$ loja A Colossal 10\% dos colaboradores "concordam parcialmente" que o trabalhador motivado desempenha melhor sua função e 50\% "concordam totalmente".

Os gráficos mostram que o trabalhador motivado desempenha melhor a sua função, embora a loja Pontal apresente opiniões diversas. 
19. Você tem recursos adequados e

suficientes para realizar sua função.

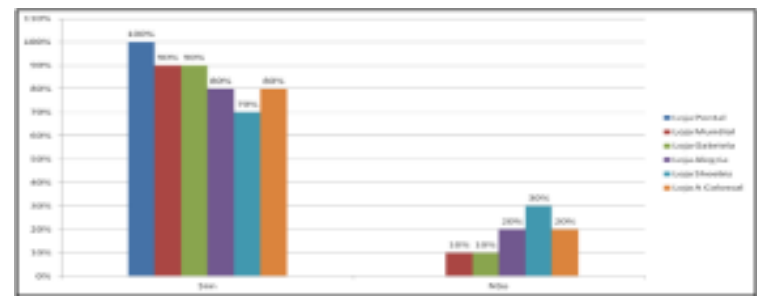

Na loja Pontal 100\% dos colaboradores responderam que possui ferramentas adequadas para exercer sua função.

Na loja Mundial 90\% dos colaboradores responderam que possui ferramentas adequadas, para exercer sua função e 10\% alegam que não possuem.

Na loja Gabriela 90\% dos colaboradores responderam que possui ferramentas adequadas, para exercer sua função e 10\% alegam que não possuem.

Na loja Alegria 80\% dos colaboradores responderam que possui ferramentas adequadas para exercer sua função e $20 \%$ alegam que não possuem.

Na loja Shoebiz 70\% dos colaboradores responderam que possui ferramentas adequadas para exercer sua função e $30 \%$ alegam que não possuem.

$\mathrm{Na}$ loja A Colossal $80 \%$ dos colaboradores responderam que possui ferramentas adequadas para exercer sua função e 20\% alegam que não possuem.

Quanto aos recursos adequados para realizar as atividades, os gráficos mostram de forma positiva, com índice negativo muito pequeno, o qual não interfere na motivação dos colaboradores, mas contribui para agilidade e resultados de seus trabalhos.

20. Você esta satisfeita com o seu ambiente de trabalho.

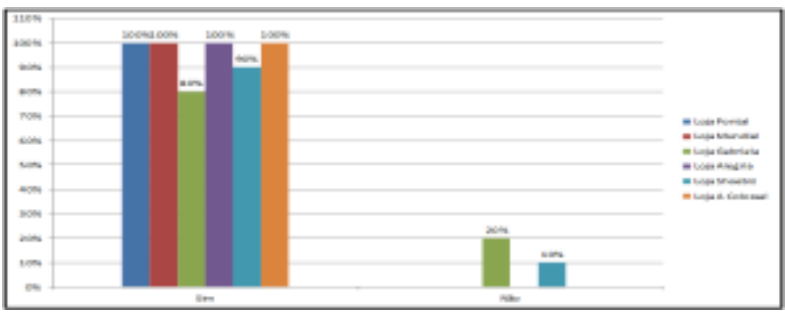

$\mathrm{Na}$ loja Pontal os colaboradores dizem estar 100\% satisfeitos com o ambiente de trabalho.

Na loja Mundial os colaboradores dizem estar 100\% satisfeitos com o ambiente de trabalho.

Na loja Gabriela os colaboradores dizem estar 100\% satisfeitos com o ambiente de trabalho.

$\mathrm{Na}$ loja Alegria os colaboradores dizem estar 100\% satisfeitos com o ambiente de trabalho.

$\mathrm{Na}$ loja Shoebiz os colaboradores dizem estar $90 \%$ satisfeitos com o ambiente de trabalho e 10\% estão insatisfeitos.

$\mathrm{Na}$ loja A Colossal os colaboradores dizem estar 100\% satisfeitos com o ambiente de trabalho.

Comparando os gráficos todos estão satisfeitos com o ambiente de trabalho. 
21. No seu ambiente de trabalho há conflitos.

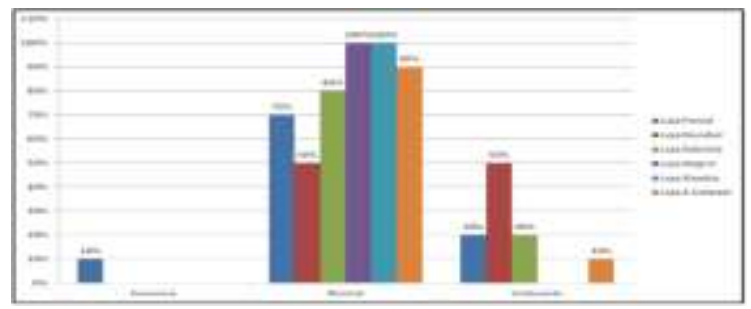

Na loja Pontal 10\% dos colaboradores dizem que em seu ambiente de trabalho o conflito é "excessivo", 70\% dizem que é "normal" e 20\% dizem que é "irrelevante".

Na loja Mundial 50\% dos colaboradores dizem que em seu ambiente de trabalho o conflito é "normal" e 50\% dizem que é "irrelevante".

Na loja Gabriela 80\% dos colaboradores dizem que em seu ambiente de trabalho o conflito é "normal" e 20\% dizem que é "irrelevante".

Na loja Alegria 100\% dos colaboradores dizem que em seu ambiente de trabalho o conflito é "normal".

Na loja Shoebiz 100\% dos colaboradores dizem que em seu ambiente de trabalho o conflito é "normal".

$\mathrm{Na}$ loja A Colossal $90 \%$ dos colaboradores dizem que em seu ambiente de trabalho o conflito é "normal" e 10\% dizem que é "irrelevante".

Nota-se que o conflito em todas as empresas, é visto de forma normal, complementando resposta da pergunta 20 , onde mostra que apesar do conflito ser considerado normal, todos os funcionários estão satisfeitos com seu ambiente de trabalho.
22. Você sente-se reconhecido no

ambiente de trabalho.

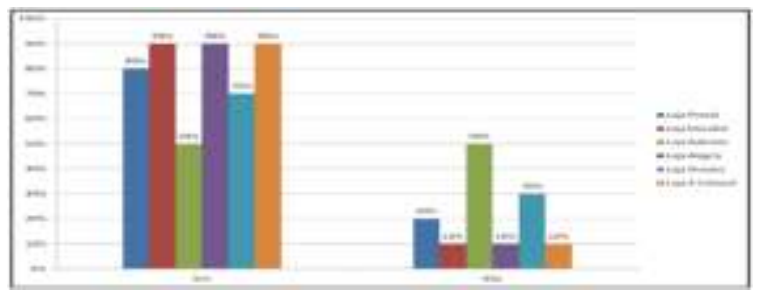

Na loja Pontal 80\% dos colaboradores dizem se sentir reconhecido em seu ambiente de trabalho e apenas 20\% dizem não se sentir reconhecido.

Na loja Mundial 90\% dos colaboradores dizem se sentir reconhecido em seu ambiente de trabalho e apenas 10\% dizem não se sentir reconhecido.

Na loja Gabriela 50\% dos colaboradores dizem se sentir reconhecido em seu ambiente de trabalho e $50 \%$ dizem não se sentir reconhecido.

Na loja Alegria 90\% dos colaboradores dizem se sentir reconhecido em seu ambiente de trabalho e apenas 10\% dizem não se sentir reconhecido.

$\mathrm{Na}$ loja Shoebiz 70\% dos colaboradores dizem se sentir reconhecido em seu ambiente de trabalho e apenas 30\% dizem não se sentir reconhecido.

$\mathrm{Na}$ loja A Colossal 90\% dos colaboradores dizem se sentir reconhecido em seu ambiente de trabalho e apenas 10\% dizem não se sentir reconhecido.

Nota-se que grande parte dos colaboradores são reconhecidos pelo seu trabalho e esforço, o que faz com que gere motivação e diminua conflitos na empresa. 
23. As normas, regras e procedimentos estão sendo exercidas corretamente.

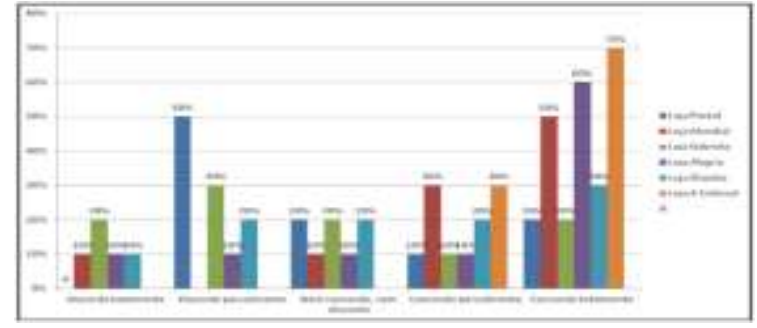

Na loja Pontal 50\% dos colaboradores “discordam parcialmente" que as normas e procedimentos estão sendo exercidas corretamente, $20 \%$ "nem concordam e nem discordam", 10\% "concordam parcialmente" e $20 \%$ "concordam totalmente".

Na loja Mundial 10\% dos colaboradores "discordam totalmente" que as normas e procedimentos estão sendo exercidas corretamente, $10 \%$ "nem concordam e nem discordam", 30\% "concordam parcialmente" e $50 \%$ "concordam totalmente".

Na loja Gabriela 20\% dos colaboradores "discordam totalmente" que as normas e procedimentos estão sendo exercidas corretamente, 30\% "discordam parcialmente", $20 \%$ "nem concordam e nem discordam", $10 \%$ "concordam parcialmente" e 20\% "concordam totalmente".

Na loja Alegria 10\% dos colaboradores "discordam totalmente" que as normas e procedimentos estão sendo exercidas corretamente, $10 \%$ "discordam parcialmente", $10 \%$ "nem concordam e nem discordam", $10 \%$ “concordam parcialmente" e 60\% "concordam totalmente".
Na loja Shoebiz 10\% dos colaboradores "discordam totalmente" que as normas e procedimentos estão sendo exercidas corretamente, 20\% "discordam parcialmente", $20 \%$ "nem concordam e nem discordam", $20 \%$ "concordam parcialmente" e 30\% "concordam totalmente".

$\mathrm{Na}$ loja A Colossal 30\% dos colaboradores "concordam parcialmente" que as normas e procedimentos estão sendo exercidas corretamente e 70\% "concordam totalmente".

Em relação ao cumprimento das normas e regras as opiniões são diversas, mas não interfere em um bom ambiente de trabalho ou motivação para exercer suas funções.

\section{Como você avalia a} comunicação interna entre gestores e subordinados.

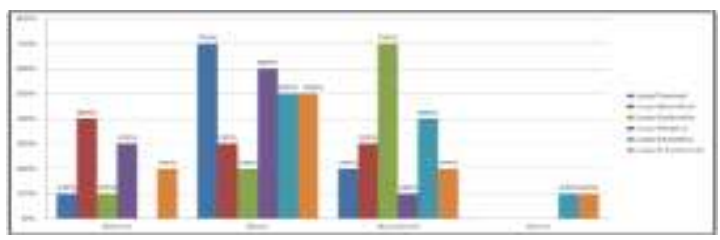

Na loja Pontal 10\% dos colaboradores classificam a comunicação interna entre gestores como "ótima", $70 \%$ como "boa" e $20 \%$ como "razoável”.

$\mathrm{Na}$ loja Mundial 40\% dos colaboradores classificam a comunicação interna entre gestores como "ótima", 30\% como "boa" e 30\% como "razoável”.

Na loja Gabriela 10\% dos colaboradores classificam a comunicação interna entre gestores 
como "ótima", 20\% como "boa" e 70\% como “razoável”.

$\mathrm{Na}$ loja Alegria 30\% dos colaboradores classificam a comunicação interna entre gestores como "ótima", 60\% como "boa" e 10\% como “razoável”.

$\mathrm{Na}$ loja Shoebiz 50\% dos colaboradores classificam a comunicação interna entre gestores como "boa", 40\% como "razoável" e 10\% como "ruim".

$\mathrm{Na}$ loja A Colossal $20 \%$ dos colaboradores classificam a comunicação interna entre gestores como "ótimo", 50\% como "boa", 20\% como "razoável" e 10\% como "ruim".

Para a comunicação entre gestores e subordinados houve respostas diversas, a qual justifica as opiniões também diversas em relação ao cumprimento das normas e regras. Nota-se que não interfere na motivação e desempenho da maior parte dos colaboradores entrevistados.

25. O diálogo é utilizado para resolver os problemas de trabalho.

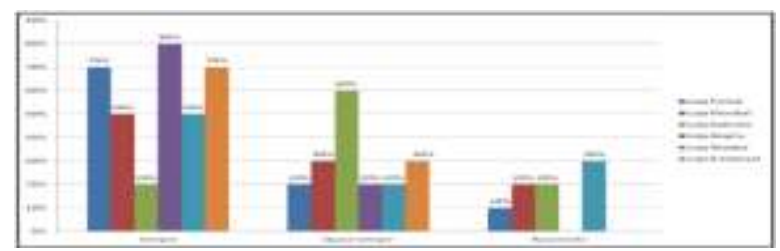

Na loja Pontal 70\% dos colaboradores responderam que o dialogo "sempre" resolve os problemas do trabalho, 20\% "quase sempre" e 10\% "raramente".

Na loja Mundial 50\% dos colaboradores responderam que o dialogo como "sempre" resolve os problemas do trabalho, 30\% "quase sempre" e 20\% "raramente".
Na loja Gabriela 20\% dos colaboradores responderam que o dialogo como "sempre" resolve os problemas do trabalho, $60 \%$ "quase sempre" e $20 \%$ "raramente".

$\mathrm{Na}$ loja Alegria 80\% dos colaboradores responderam que o dialogo como "sempre" resolve os problemas do trabalho e $20 \%$ "quase sempre".

Na loja Shoebiz 50\% dos colaboradores responderam que o dialogo como "sempre" resolve os problemas do trabalho, 20\% "quase sempre" e 30\% "raramente".

$\mathrm{Na}$ loja A Colossal $70 \%$ dos colaboradores responderam que o dialogo como "sempre" resolve os problemas do trabalho e $30 \%$ "quase sempre".

Os gráficos mostram que o diálogo é sempre utilizado para resolver qualquer problema e evitar conflitos entre lideres e colaboradores.

26. Você indicaria um colega ou familiar para uma vaga de trabalho na empresa.

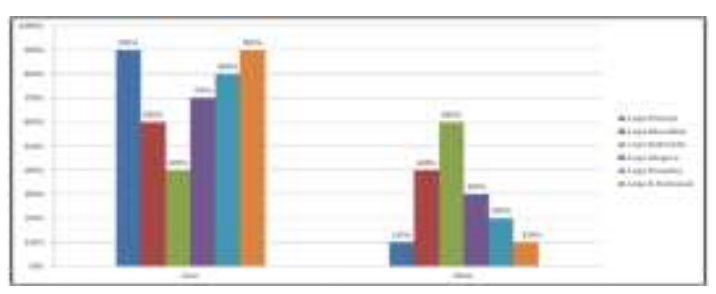

$\mathrm{Na}$ loja Pontal $90 \%$ dos seus colaboradores indicam a empresa para se trabalhar e apenas 10\% não indicam.

$\mathrm{Na}$ loja Mundial $60 \%$ dos seus colaboradores indicam a empresa para se trabalhar e $40 \%$ não indicam. 
$\mathrm{Na}$ loja Gabriela $40 \%$ dos seus colaboradores indicam a empresa para se trabalhar e 60\% não indicam.

$\mathrm{Na}$ loja Alegria $70 \%$ dos seus colaboradores indicam a empresa para se trabalhar e 30\% não indicam.

$\mathrm{Na}$ loja Pontal $80 \%$ dos seus colaboradores indicam a empresa para se trabalhar e apenas $20 \%$ não indicam.

$\mathrm{Na}$ loja A Colossal 90\% dos seus colaboradores indicam a empresa para se trabalhar e apenas 10\% não indicam.

Devido à satisfação com ambiente de trabalho entre outros benefícios, a indicação de uma vaga as colegas ou familiares é feita de forma positiva, exceto na loja Gabriela onde teve o maior índice negativo de indicação.

27. Você recomendaria essa empresa para se trabalhar:

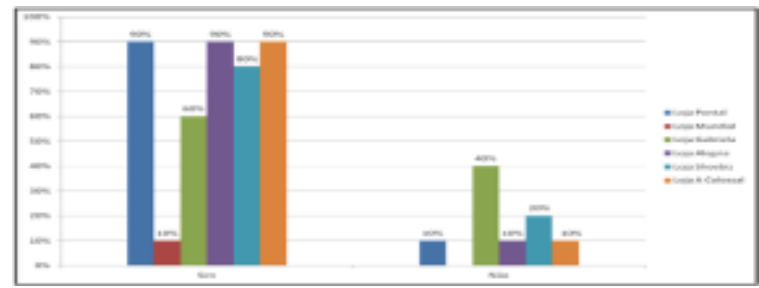

$\mathrm{Na}$ loja Pontal $90 \%$ dos seus colaboradores recomendam a empresa para se trabalhar e apenas 10\% não recomendam.

$\mathrm{Na}$ loja Mundial 100\% dos seus colaboradores recomendam a empresa para se trabalhar.

$\mathrm{Na}$ loja Gabriela $60 \%$ dos seus colaboradores recomendam a empresa para se trabalhar e apenas 10\% não recomendam.
$\mathrm{Na}$ loja Alegria $90 \%$ dos seus colaboradores recomendam a empresa para se trabalhar e apenas 10\% não recomendam.

$\mathrm{Na}$ loja Shoebiz 60\% dos seus colaboradores recomendam a empresa para se trabalhar e apenas $20 \%$ não recomendam.

$\mathrm{Na}$ loja A Colossal 90\% dos seus colaboradores recomendam a empresa para se trabalhar e apenas 10\% não recomendam.

Conforme a analise dos gráficos, os colaboradores recomendam suas respectivas empresas para se trabalhar, contradizendo informações do gráfico anterior, onde funcionários da Loja Gabriela, teve um percentual alto de não indicar um amigo ou familiar.

28. Como você avalia o trabalho em equipe.

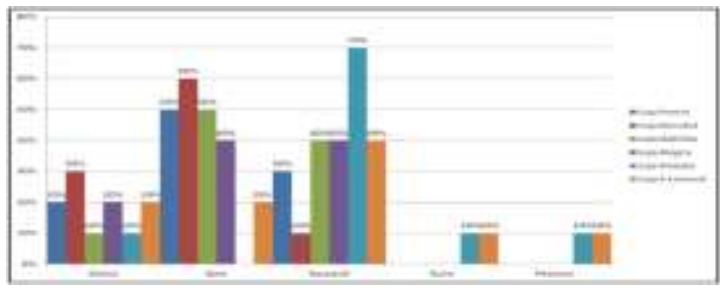

Na loja Pontal 20\% dos colaboradores classificam o trabalho em equipe como ótimo, $50 \%$ como bom e 30\% como razoável.

$\mathrm{Na}$ loja Mundial 30\% dos colaboradores classificam o trabalho em equipe como ótimo, $60 \%$ como bom e 10\% como razoável.

$\mathrm{Na}$ loja Mundial 30\% dos colaboradores classificam o trabalho em equipe como ótimo, 60\% como bom e 10\% como razoável.

$\mathrm{Na}$ loja Alegria 20\% dos colaboradores classificam o trabalho em equipe como ótimo, $40 \%$ como bom e $40 \%$ como razoável. 
Na loja Shoebiz 10\% dos colaboradores classificam o trabalho em equipe como ótimo, $70 \%$ como razoável, $10 \%$ como ruim e 10\% como péssimo.

$\mathrm{Na}$ loja A Colossal 20\% dos colaboradores classificam o trabalho em equipe como ótimo, $20 \%$ como bom, $40 \%$ como razoável, 10\% como ruim e 10\% como péssimo.

O trabalho em equipe foi avaliado de forma satisfatória e positiva, mesmo havendo diversidade nas respostas, isto justifica as respostas positiva da pergunta 20: Você esta satisfeita com o seu ambiente de trabalho, mostrando também há motivação.

\subsection{Resultado da Pesquisa de Campo - Clientes}

1. Simpatia e Cordialidade no Atendimento

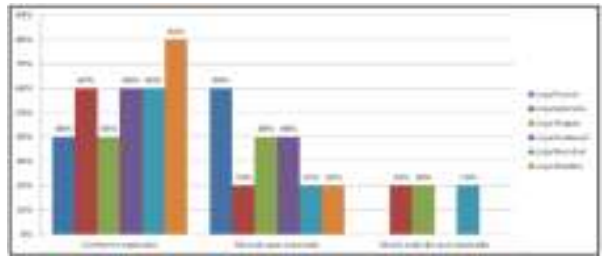

$\mathrm{Na}$ loja Pontal os clientes entrevistados responderam que: para simpatia e cordialidade no atendimento $40 \%$ está conforme o esperado e 60\% apontam que está mais do que o esperado.

$\mathrm{Na}$ loja Mundial os clientes entrevistados responderam que: para simpatia e cordialidade no atendimento $100 \%$ apontam que está mais do que o esperado.

Na loja Gabriela os clientes entrevistados responderam que: para simpatia e cordialidade no atendimento $60 \%$ está conforme o esperado,
20\% apontam que está mais do que o esperado e $20 \%$ muito mais do que o esperado.

$\mathrm{Na}$ loja Alegria os clientes entrevistados responderam que: para simpatia e cordialidade no atendimento $40 \%$ está conforme o esperado, $40 \%$ apontam que está mais do que o esperado e $20 \%$ muito mais do que o esperado.

$\mathrm{Na}$ loja A Colossal os clientes entrevistados responderam que: para simpatia e cordialidade no atendimento $60 \%$ está conforme o esperado e $40 \%$ apontam que está mais do que o esperado.

$\mathrm{Na}$ loja Shoebiz os clientes entrevistados responderam que: para simpatia e cordialidade no atendimento $80 \%$ está conforme o esperado, $20 \%$ apontam que está mais do que o esperado.

Conforme pode-se observar nestes gráficos, todas as respostas apresentam percentuais superiores ao padrão de atendimento esperado pelo cliente.

2. Capacidade de identificar a sua necessidade

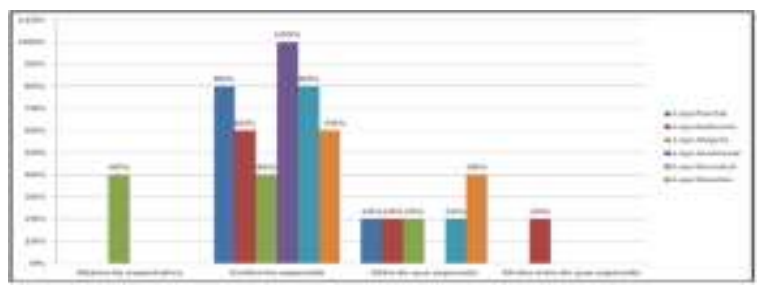

$\mathrm{Na}$ loja Pontal os clientes entrevistados responderam que: a capacidade de identificar a sua necessidade $80 \%$ está conforme o esperado e $20 \%$ apontam que está mais do que o esperado.

Na loja Mundial os clientes entrevistados responderam que: A Capacidade de identificar a 
sua necessidade $80 \%$ está conforme o esperado e 20\% apontam que está mais do que o esperado.

$\mathrm{Na}$ loja Gabriela os clientes entrevistados responderam que: A Capacidade de identificar a sua necessidade $60 \%$ está conforme o esperado, $20 \%$ apontam que está mais do que o esperado e $20 \%$ muito mais do que o esperado.

$\mathrm{Na}$ loja Alegria os clientes entrevistados responderam que: A Capacidade de identificar a sua necessidade $40 \%$ abaixo da expectativa, $40 \%$ está conforme o esperado e $20 \%$ apontam que está mais do que o esperado.

$\mathrm{Na}$ loja A Colossal os clientes entrevistados responderam que: A Capacidade de identificar a sua necessidade 100\% está conforme o esperado.

$\mathrm{Na}$ loja Shoebiz os clientes entrevistados responderam que: A Capacidade de identificar a sua necessidade $60 \%$ está conforme o esperado e 40\% apontam que está mais do que o esperado.

Conforme pode-se observar nestes gráficos, somente a loja Alegria apresenta um percentual (40\%) inferior ao padrão de atendimento esperado pelo cliente e, as demais respostas apresentam percentuais superiores ao padrão de atendimento esperado pelo cliente.

3. Rapidez na apresentação do produto

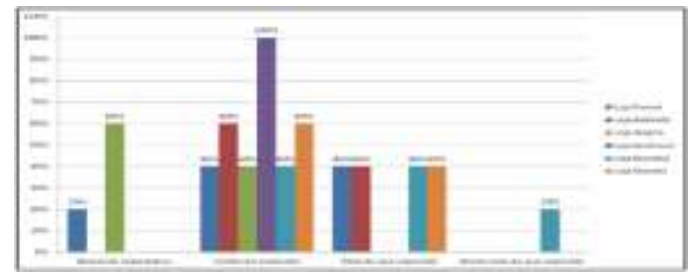

$\mathrm{Na}$ loja Pontal os clientes entrevistados responderam que: A Rapidez na apresentação do produto $20 \%$, esta abaixo da expectativa, $40 \%$ está conforme o esperado e $40 \%$ apontam que está mais do que o esperado.

$\mathrm{Na}$ loja Mundial os clientes entrevistados responderam que: A Rapidez na apresentação do produto $40 \%$ está conforme o esperado, $40 \%$ apontam que está mais do que o esperado e $20 \%$ esta muito mais do que o esperado.

$\mathrm{Na}$ loja Gabriela os clientes entrevistados responderam que: A Rapidez na apresentação do produto $60 \%$ está conforme o esperado e $40 \%$ apontam que está mais do que o esperado.

$\mathrm{Na}$ loja Alegria os clientes entrevistados responderam que: A Rapidez na apresentação do produto $60 \%$ está abaixo da expectativa e $40 \%$ apontam que está conforme o esperado.

$\mathrm{Na}$ loja A Colossal os clientes entrevistados responderam que: A Rapidez na apresentação do produto 100\% está conforme o esperado.

Na loja Shoebiz os clientes entrevistados responderam que: A Rapidez na apresentação do produto $60 \%$ está conforme o esperado e $40 \%$ apontam que está mais do que o esperado.

Conforme pode-se observar nestes gráficos,somente a loja Alegria apresenta um percentual $(60 \%)$ inferior ao padrão de atendimento esperado pelo cliente e, as demais respostas apresentam percentuais superiores ao padrão de atendimento esperado pelo cliente.

4. Qualidade dos serviços

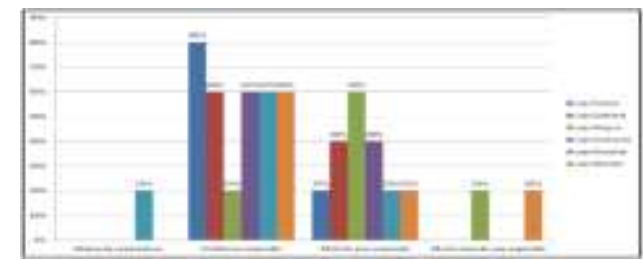


$\mathrm{Na}$ loja Pontal os clientes entrevistados responderam que: A Qualidade dos serviços $80 \%$ está conforme o esperado e $20 \%$ apontam que está mais do que o esperado.

$\mathrm{Na}$ loja Mundial os clientes entrevistados responderam que: A Qualidade dos serviços $20 \%$ está abaixo da expectativa, $60 \%$ conforme esperado e $20 \%$ mais do que o esperado.

$\mathrm{Na}$ loja Gabriela os clientes entrevistados responderam que: A Qualidade dos serviços $60 \%$ está conforme o esperado e $40 \%$ apontam que está mais do que o esperado.

$\mathrm{Na}$ loja Alegria os clientes entrevistados responderam que: A Qualidade dos serviços $20 \%$ está conforme o esperado, $60 \%$ apontam que está mais do que o esperado e $20 \%$ muito mais do que o esperado.

$\mathrm{Na}$ loja A Colossal os clientes entrevistados responderam que: A Qualidade dos serviços $60 \%$ está conforme o esperado e $40 \%$ apontam que está mais do que o esperado.

$\mathrm{Na}$ loja Shoebiz os clientes entrevistados responderam que: A Qualidade dos serviços $60 \%$ está conforme o esperado, 20\% apontam que está mais do que o esperado e $20 \%$ muito mais do que esperado.

Observa-se nestes gráficos, que somente a loja Mundial apresenta um percentual (20\%) inferior ao padrão de atendimento esperado pelo cliente e, as demais respostas apresentam percentuais superiores ao padrão de atendimento esperado pelo cliente.
5. Considera-se satisfeito com o atendimento realizado

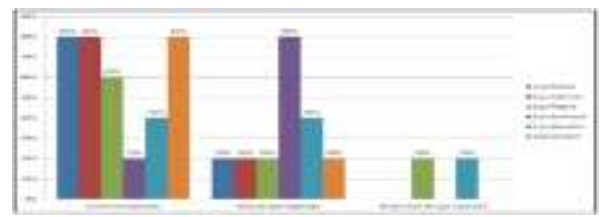

$\mathrm{Na}$ loja Pontal os clientes entrevistados responderam que: Consideram-se satisfeito com o atendimento realizado $80 \%$ está conforme o esperado e $20 \%$ apontam que está mais do que o esperado.

$\mathrm{Na}$ loja Mundial os clientes entrevistados responderam que: Consideram-se satisfeito com o atendimento realizado $40 \%$ está conforme o esperado, 40\% apontam que está mais do que o esperado e $20 \%$ esta muito mais do que esperado.

$\mathrm{Na}$ loja Gabriela os clientes entrevistados responderam que: Consideram-se satisfeito com o atendimento realizado $80 \%$ está conforme o esperado e $20 \%$ apontam que está mais do que o esperado.

$\mathrm{Na}$ loja Alegria os clientes entrevistados responderam que: Consideram-se satisfeito com o atendimento realizado $60 \%$ está conforme o esperado, 20\% apontam que está mais do que o esperado e $20 \%$ esta muito mais do que esperado.

$\mathrm{Na}$ loja A Colossal os clientes entrevistados responderam que: Consideram-se satisfeito com o atendimento realizado $20 \%$ está conforme o esperado e $80 \%$ apontam que está mais do que o esperado. 
$\mathrm{Na}$ loja Shoebiz os clientes entrevistados responderam que: Consideram-se satisfeito com o atendimento realizado $80 \%$ está conforme o esperado e $20 \%$ apontam que está mais do que o esperado.

Conforme pode-se observar nestes gráficos, todas as respostas apresentam percentuais superiores ao padrão de atendimento esperado pelo cliente.

6. Você recomendaria essa loja para amigos e/ou conhecidos?

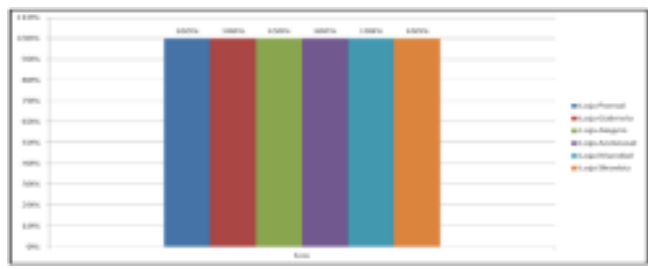

$\mathrm{Na}$ loja Pontal $100 \%$ dos clientes entrevistados responderam que recomendaria essa loja para amigos e/ou conhecidos.

$\mathrm{Na}$ loja Mundial 100\% dos clientes entrevistados responderam que recomendaria essa loja para amigos e/ou conhecidos.

$\mathrm{Na}$ loja Gabriela 100\% dos clientes entrevistados responderam que recomendaria essa loja para amigos e/ou conhecidos.

$\mathrm{Na}$ loja Alegria 100\% dos clientes entrevistados responderam que recomendaria essa loja para amigos e/ou conhecidos.

$\mathrm{Na}$ loja A Colossal 100\% dos clientes entrevistados responderam que recomendaria essa loja para amigos e/ou conhecidos.

$\mathrm{Na}$ loja Shoebiz 100\% dos clientes entrevistados responderam que recomendaria essa loja para amigos e/ou conhecidos.
Através dos resultados podemos observar que, independente do grau de insatisfação do cliente, este retorna a loja e indica para terceiros. A probabilidade de indicação é de 100\% para todas as lojas.

De acordo com as respostas obtidas, o índice de insatisfação nos quesitos "Qualidade do serviço e Rapidez na apresentação do produto" comparado aos aspectos "Simpatia e Cordialidade no Atendimento, a Capacidade de identificar a necessidade do cliente, e a Satisfação com o atendimento realizado" não são significativos, porque o índice apresentado nos resultados obtidos é positivo.

\section{Considerações Finais}

O presente estudo teve como propósito apresentar uma analise sobre a qualidade no ambiente organizacional, tendo como o impacto do serviço prestado e a sua consequência na percepção do cliente, ou seja, como o funcionário transmite sua motivação, satisfação dentre outros aspectos para o cliente final.

Procurou-se mostrar de forma clara a evolução que ocorreu e vem ocorrendo nos dias atuais nas relações entre empresas e funcionários e, qual o impacto no convívio com os clientes. Se olharmos para o passado veremos que essa importância só se deu após um estudo feito por Elton Mayo, que mostrou qual sua importância para ambas às partes, através de ocorrências, como a exigência dos funcionários para com o tratamento mais qualificado e para conquistas 
pessoais e profissionais. Isto mostrou que as empresas passaram a preocupar-se mais com o estado do ser humano do que antigamente, isso trouxe um ponto positivo para o trabalhador, que passaram a sugerir melhorias para o desempenho do seu serviço e principalmente decidir a melhor maneira de se trabalhar.

Vimos que cada empresa tem sua cultura, ou seja, políticas, filosofia e regras que devem ser cumpridas por todos os colaboradores em que nela atuam. Geralmente essas normas podem trazer um clima favorável para a empresa, fazendo com que os trabalhadores se sintam confortáveis, pois é o local em que passam a maior parte do tempo, porém, essa cultura pode não agradar a todos os colaboradores, devido à idiossincrasia de cada pessoa sobre a empresa.

Quando há uma oposição generalizada sobre a cultura da empresa, pode causar um clima negativo entre os líderes e subordinados e consequentemente um conflito, ou seja, uma oposição de ideias. Esse conflito pode ser positivo quando a empresa descobre a real causa e busca entender para poder administrar da melhor forma, mas também pode ser negativo quando a empresa ou líder de uma determinada equipe ignora e não se preocupa em compreender o pensamento do colaborador, acarretando no prejuízo e na perda dos funcionários, afetando negativamente todo o conjunto organizacional. Verificamos que uma das maneiras de se administrar bem um conflito é buscar saber da motivação do funcionário com a empresa, algo em que o departamento de
Recursos Humanos, líderes e gerentes devem observar sempre.

Consideramos que um funcionário motivado realiza com eficiência seu trabalho trazendo bons resultados para organização, e principalmente um bom trabalho em equipe, estimulando todos os funcionários a buscar a melhor maneira de aumentar o desempenho da equipe.

Por meio da pesquisa de campo efetuada no ramo de comercio e varejo diante de questões sobre o clima e cultura das empresas pesquisadas, verificou-se que o investimento ainda é insuficiente, devido à falta de oportunidade, a não exigência de escolaridade e pressão exercida sobre os funcionários.

As visitas feitas nas lojas, onde os funcionários tem um contato maior com o cliente, identificamos que muitos deles estão motivados com a empresa, por existir um ambiente agradável, pois o tratamento é igual para todos, porém não há elogio quando o trabalho é bem executado. Verificamos que há um índice alto de motivação referente aos benefícios que a empresa fornece, tais como salários e carga-horária, possibilitando a indicação de familiares ou conhecidos para novas vagas na empresa. Referente à resposta sobre o trabalho em equipe e a comunicação entre os gerentes e subordinados, $80 \%$ dos funcionários avaliaram que os gerentes são participativos e a há um bom trabalho em equipe. Em consequência do resultado de motivação dos funcionários com a empresa, 
90\% dos clientes entrevistados, estão satisfeito com o atendimento prestado.

Portanto concluímos que as organizações são compostas por pessoas, independentemente se a empresa presta serviço ou não. As pessoas estando insatisfeitas com a empresa o seu trabalho vai de mal a pior, mas se elas estão motivadas, o seu serviço se apresenta com qualidade fazendo com que os clientes também fiquem satisfeitos.

Considera-se que a qualidade do ambiente organizacional se deu pela necessidade de valorizar os profissionais nas empresas e que esta qualidade, está cada vez mais cobiçada por todos, porque é por meio dela que os colaboradores alcançam os seus objetivos pessoais e profissionais.

\section{Referências Bibliográficas}

AGUIAR, M. A. F. Psicologia Aplicada à Administração. 2. Ed. São Paulo: Editora Excellus, 2000.

BALÇÃO, YOLANDA FERREIRA. O comportamento humano na empresa. Rio de Janeiro: Editora FGV, 1979.

BERGAMINI, Cecília Whitaker. Motivação nas organizações. 4. ed. São Paulo : Editora Atlas, 1997.

BOWDITCH, James L. e BUONO, Anthony F. Elementos de comportamento organizacional. 3. ed. São Paulo: Editora Cengage Learning Editores, 2009.
CARPINETTI, Luiz Cesar Ribeiro. Gestão da qualidade - Conceitos e Técnicas. 2 ed. São Paulo: Ed. Atlas, 2012.

CARVALHO, MARIA do C. N. Gestão de pessoas - Col Biblioteca de Competências. SENAC Nacional, 2007.

CHANLAT, Jean F. et al. O individuo na organização - Dimensões esquecidas. Volume I. São Paulo: Editora Atlas, 1996.

CHANLAT, Jean F. et al. O individuo na organização - Dimensões esquecidas. Volume II. São Paulo: Editora Atlas, 2001.

CHANLAT, Jean $F$. et al. O individuo na organização - Dimensões esquecidas. Volume III. São Paulo: Editora Atlas, 2007.

CHIAVENTO, Idalberto. Gerenciando

Pessoas. 3. ed. São Paulo: Editora Makron Books, 1994.

CHIAVENATO, Idalberto, Administração de

Recursos Humanos. 7. ed, Barueri: Editora Manole, 2009.

CHIAVENATO, Idalberto, Introdução à Teoria geral da administração. 6 ed, Rio de Janeiro: Editora Campus, 2000.

CHIAVENATO, Idalberto. Recursos Humanos. 7. ed. compacta. Rio de Janeiro: Editora Atlas, 2002.

CHIAVENATO, Idalberto. Gestão de pessoas - o novo papel dos recursos humanos nas organizações. Rio de Janeiro: Editora Campus, 1999.

CHIAVENATO, Idalberto. Administração de empresas - uma abordagem contigencial. 3 . ed. São Paulo: Editora Makron Books,1994. 
CHIAVENATO, Idalberto. Introdução à teoria geral da administração - uma visão abrangente e moderna administração das organizações. 7. ed. Rio de Janeiro: Editora Elsevier, 2005.

CHIAVENATO, I.; SAPIRO, A. Planejamento estratégico - fundamentos e aplicações. 3. ed. Rio de Janeiro: Editora Elieser, 2003.

DAVIS, Keith.; NEWSTRON, John W. Comportamento Humano no Trabalho Uma Abordagem Psicológica. Vol. 1. São Paulo: Editora Cengage Learning, 1992.

DRUKER, Peter F. Administração sem fins lucrativos princípios e práticas. 5. ed. São Paulo: Editora Pioneira Administração de Negócios, 1999.

FERREIRA, Ademir A.: REIS, A. C. F.; PEREIRA, M. I. Gestão empresarial: de Taylor dos nossos dias. São Paulo: Editora Cengage Learning, 2011.

FIORELlI, Joé Osmir. Psicologia para Administradores. 4. ed. São Paulo: Editora Atlas, 2004.

GALBRAITH, Jay R.; LAWLER III, Edward E. \& Associados. Organizando para competir no futuro - Estratégias para gerenciar o futuro das Organizações. São Paulo: Editora Makron Books, 1995.

GARVIN, D. A. Gerenciando a qualidade: a visão estratégica competitiva. Rio de Janeiro: Editora Qualitymark, 1992.

HARDINGHAM, A. Trabalho em equipe Você S.A. São Paulo: Editora Abril, 2000.
ÖCHE, José Carlos. Fundamentos da metodologia cientifica: tória da ciência e iniciação á pesquisa. Rio de Janeiro: Editora Vozes, 1997.

KOTLER, P. Administração de marketing. 10. ed. São Paulo: Novo Milênio, 2000.

KREITNER, Robert.; KINICKI, Ângelo. Comportamento Organizacional. 2. ed. São Paulo: Editora Artmed, 2007.

LACOMBE, Francisco J. M. Recursos Humanos - Princípios e Tendências. São Paulo: Editora Saraiva, 2005.

LACOMBE, F.J. Recursos Humanos Princípios e Tendências. São Paulo: Saraiva, 2005.

LAKATOS, E. M. Fundamentos da metodologia cientifica. 6. ed. São Paulo: Editora Atlas, 2006.

LANZANA, A. E. T. Economia brasileira: fundamentos e atualidades. São Paulo: Editora Atlas, 2001.

MACHELINE, C. et. al. Marketing (Administração) - gestão de marketing. São Paulo: Editora Saraiva, 2003.

MASLOW, A. H. Motivacion Y Personalidad. Barcelona: Harper \& Brother, 1954.

MAXIMIANO, Antônio Cesar Amaru, Introdução à administração. 4. ed. São Paulo: Editora Atlas, 1995.

MAXIMIANIO, A. C. A. Teoria geral da administração: da escola científica á competitividade na economia globalizada. 2 . ed. São Paulo: Editora Atlas, 2000.

MOLLER, Claus. O lado humano da qualidade - Maximizando a qualidade de 
produtos e serviços através do desenvolvimento das pessoas. 11 ed. São Paulo: Editora Pioneira Administração de Negócios, 1997.

MOT'TA, Fernando C. P. Teoria geral da Administração uma introdução. $22^{\circ} \mathrm{Ed}$. São Paulo: Editora Pioneira, 1998.

OLIVEIRA, D. P. R. Sistemas, organizações e métodos: uma abordagem gerencial. 13. ed. São Paulo: Editora Atlas, 2002.

OLIVEIRA, D. P. R. Planejamento Estratégico. São Paulo: Editora Atlas, 2005.

PALOMINOS, Roberto. Nem acaso, Nem milagre - A gestão do comportamento. 2. ed. São Paulo: Editora Gente, 1997.

ROBBINS, STEPHEN PAUL. Comportamento organizacional. 11. ed. São Paulo: Editora Pearson Prentice Hall, 2005.

ROBBINS, STEPHEN PAUL. Comportamento organizacional. 9. ed. São Paulo: Editora Pearson Prentice Hall, 2002.

SOUZA, M. M. M. Organização do trabalho na produção. São Paulo: Editora Universal Comercial Software Ltda, 2013.

SOUZA, M. M. M. Comunicação interna nas empresas - tese de Doutorado, PUCSP. 2005. TAYLOR, Frederico W. Princípios da Administração Cientifica. $8^{\circ}$ Ed. São Paulo: Editora Atlas, 1990.
VERGARA, S. C. Projetos de pesquisa em administração. São Paulo: Editora Atlas, 2000. VROON, Victor H. Work and Motivation. New York: John Wiley, 1964.

VROON, Victor H. Gestão de Pessoas, não de Pessoal: Os Melhores Métodos de Motivação e Avaliação de Desempenho. Rio de Janeiro: Campus, 1997.

WRIGHT, P.; KROLL, M. J.; PARNE, J. Administração estratégica - Conceitos. São Paulo: Editora Atlas, 2000.

Melhores empresas para se trabalhar - Revista Exame, 2002.

As 100 melhores empresas para se trabalhar Você S/A 2004.

\section{Referencias Bibliográficas Eletrônicas}

www.gruposer.com.br, acessado em 20/08/2013;

www.godri.com.br, acessado em 20/08/2013; www.rh.com.br, acessado em 20/08/2013; www.golfinho.com.br, acessado em 20/08/2013; www.abrae.com.br, acessado em 20/08/2013; 


\section{ADENDO I - QUESTIONÁRIO DA PESQUISA DE CAMPO AOS FUNCIONÁRIOS}

Este questionário tem a finalidade de verificar se um funcionário satisfeito com a empresa em que trabalha, faz um bom atendimento ao cliente.

Se puder respondê-lo contribuirá com o trabalho científico dos alunos das Faculdades integradas Campos Salles.

Desde já agradecemos a sua atenção e colaboração.

\begin{tabular}{|c|c|}
\hline $\begin{array}{l}\text { 1 -Idade: } \\
\text { ( ) Até } 25 \text { anos; } \\
\text { ( ) Acima de } 25 \text { anos e até } 35 \text { anos; } \\
\text { ( ) Acima de } 35 \text { anos e até } 45 \text { anos; } \\
\text { ( ) Acima de } 45 \text { anos e até } 55 \text { anos; } \\
\text { ( ) Acima de } 55 \text { anos. }\end{array}$ & $\begin{array}{l}\text { 2-Sexo: } \\
\text { ( ) Masculino; } \\
\text { ( ) Feminino. }\end{array}$ \\
\hline \multicolumn{2}{|l|}{$\mathrm{x}$} \\
\hline $\begin{array}{l}3 \text { - Escolaridade: } \\
\text { ( ) Ensino Fundamental Incompleto; } \\
\text { ( ) Ensino Fundamental; } \\
\text { ( ) Ensino Médio Incompleto; } \\
\text { ( ) Ensino Médio; } \\
\text { ( ) Ensino Superior Incompleto; } \\
\text { ( ) Ensino Superior; } \\
\text { ( ) Pós-Graduação Lato Sensu; } \\
\text { ( ) Outros. Especifique: }\end{array}$ & $\begin{array}{l}4 \text { - Há quanto tempo trabalha na empresa? } \\
\text { ( ) Até } 5 \text { anos; } \\
\text { ( ) Acima de } 5 \text { anos e até } 10 \text { anos; } \\
\text { ( ) Acima de } 10 \text { anos e até } 15 \text { anos; } \\
\text { ( ) Acima de } 15 \text { anos e até } 20 \text { anos; } \\
\text { ( ) Acima de } 20 \text { anos. }\end{array}$ \\
\hline \multicolumn{2}{|l|}{$\mathrm{x}$} \\
\hline $\begin{array}{l}5 \text { - O que mais o motiva a trabalhar nesta empresa? } \\
\text { ( ) Salário e benefícios; } \\
\text { ( ) Reabilitar-se perante a sociedade; } \\
\text { ( ) O trabalho em si; } \\
\text { ( ) Estabilidade na empresa; } \\
\text { ( ) Plano de Carreira; } \\
\text { ( ) Outros. Especifique: }\end{array}$ & $\begin{array}{l}\text { 6 - Qual seu nível de satisfação em relação ao seu salário e } \\
\text { benefícios? } \\
\text { ( ) Insatisfeito; } \\
\text { ( ) Pouco satisfeito; } \\
\text { ( ) Satisfeito; } \\
\text { ( ) Totalmente satisfeito; } \\
\text { ( ) Supera as minhas expectativas. }\end{array}$ \\
\hline
\end{tabular}

$\mathrm{x}$

7 - Os funcionários são tratados com respeito, independente de seus cargos?

( ) Sempre;

( ) Quase sempre;

( ) Raramente;

( ) Nunca.

8 - Você é elogiado quando executa um bom trabalho?

( ) Sempre;

( ) Quase sempre;

( ) Raramente;

( ) Nunca.

$\mathrm{x}$

9 - O seu líder é participativo (faz reuniões, abre discussões, ouve e dá espaço aos funcionários para participarem dos processos de tomada de decisões, de maneira democrática)?

( ) Sempre;

( ) Quase sempre;

( ) Raramente;

( ) Nunca.

$\mathrm{x}$

11 - As orientações que você recebe sobre o seu trabalho são claras e objetivas?

( ) Sempre;

( ) Quase sempre;

( ) Raramente;

( ) Nunca.

10- O seu líder é motivador?

( ) Sempre;

( ) Quase sempre;

( ) Raramente;

( ) Nunca.

$\mathrm{x}$

13 - Você se sente realizado profissionalmente?

( ) Sim;

( ) Não;

$\begin{array}{ll}\text { ( ) Explique _- } & \text { ( ) Pouco sat } \\ \text { ( ) Satisfeito; } \\ \text { () Totalmen }\end{array}$

12 - Você vê possibilidade de crescimento de carreira na empresa? ( ) Sim;

( ) Não;

( ) Outros. Especifique: 


\begin{tabular}{|c|c|}
\hline $\begin{array}{l}15 \text { - Os gestores da empresa prezam pelo bom ambiente } \\
\text { de trabalho? } \\
\text { ( ) Sim; } \\
\text { ( ) Não; } \\
\text { ( ) Outros. Especifique: }\end{array}$ & $\begin{array}{l}16 \text { - Você tem autonomia para fazer o seu trabalho da forma que } \\
\text { considera melhor? } \\
\text { ( ) Sempre; } \\
\text { ( ) Quase sempre; } \\
\text { ( ) Raramente; } \\
\text { ( ) Nunca. }\end{array}$ \\
\hline \multicolumn{2}{|r|}{ 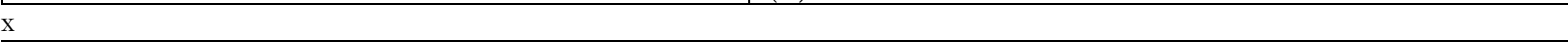 } \\
\hline $\begin{array}{l}17 \text { - Seu gestor exerce pressão sobre seu ritmo de } \\
\text { trabalho? } \\
\text { ( ) Sim; } \\
\text { ( ) Não; } \\
\text { ( ) Outros. Especifique: }\end{array}$ & $\begin{array}{l}18 \text { - Em sua opinião, o trabalhador motivado desempenha melhor } \\
\text { a sua função. } \\
\text { ( ) - Discordo totalmente; } \\
\text { ( ) - Discordo parcialmente; } \\
\text { ( ) - Nem concordo, nem discordo; } \\
\text { ( ) - Concordo parcialmente; } \\
\text { ( ) - Concordo totalmente. }\end{array}$ \\
\hline \multicolumn{2}{|c|}{ 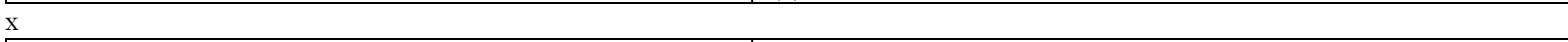 } \\
\hline $\begin{array}{l}19 \text { - Você tem recursos adequados e suficientes para } \\
\text { realizar sua função. } \\
\text { ( ) Sim; } \\
\text { ( ) Não; } \\
\text { ( ) Outros. Especifique: }\end{array}$ & $\begin{array}{l}20 \text { - Você esta satisfeita com o seu ambiente de trabalho. } \\
\text { ( ) - Sim; } \\
\text { ( ) - Não. Por quê? }\end{array}$ \\
\hline \multicolumn{2}{|l|}{$x$} \\
\hline $\begin{array}{l}21 \text { - No seu ambiente de trabalho há conflitos. } \\
\text { ( ) - Excessivo; } \\
\text { ( ) - Normal; } \\
\text { ( ) - Irrelevante. }\end{array}$ & $\begin{array}{l}22 \text { - Você sente-se reconhecido no ambiente de trabalho. } \\
\text { ( ) - Sim; } \\
\text { ( ) - Não. }\end{array}$ \\
\hline \multicolumn{2}{|l|}{$x$} \\
\hline $\begin{array}{l}23 \text { - As normas, regras e procedimentos estão sendo } \\
\text { exercidas corretamente. } \\
\text { ( ) - Discordo totalmente; } \\
\text { ( ) - Discordo parcialmente; } \\
\text { ( ) - Nem concordo, nem discordo; } \\
\text { ( ) - Concordo parcialmente; } \\
\text { ( ) - Concordo totalmente. }\end{array}$ & $\begin{array}{l}24 \text { - Como você avalia a comunicação interna entre gestores e } \\
\text { subordinados. } \\
\text { ( ) Ótimo; } \\
\text { ( ) Bom; } \\
\text { ( ) Razoável; } \\
\text { ( ) Ruim; } \\
\text { ( ) Péssimo. }\end{array}$ \\
\hline \multicolumn{2}{|l|}{$\mathrm{x}$} \\
\hline $\begin{array}{l}25 \text { - O diálogo é utilizado para resolver os problemas de } \\
\text { trabalho. } \\
\text { ( ) Sempre; } \\
\text { ( ) Quase sempre; } \\
\text { ( ) Raramente; } \\
\text { ( ) Nunca. }\end{array}$ & $\begin{array}{l}26 \text { - Você indicaria um colega ou familiar para uma vaga de } \\
\text { trabalho na empresa } \\
\text { ( ) - Sim; } \\
\text { ( ) - Não; }\end{array}$ \\
\hline \multicolumn{2}{|l|}{$\mathrm{x}$} \\
\hline $\begin{array}{l}27 \text { - Você recomendaria essa empresa para se trabalhar: } \\
\text { ( ) - Sim; } \\
\text { ( ) - Não; }\end{array}$ & $\begin{array}{l}28 \text { - Como você avalia o trabalho em equipe. } \\
\text { ( ) Ótimo; } \\
\text { ( ) Bom; } \\
\text { ( ) Razoável; } \\
\text { ( ) Ruim; } \\
\text { ( ) Péssimo. }\end{array}$ \\
\hline
\end{tabular}

\section{ADENDO II - QUESTIONÁRIO DA PESQUISA DE CAMPO AOS CLIENTES}

Este questionário tem a finalidade de verificar a satisfação dos clientes que frequentam essa loja.

Se puder respondê-lo contribuirá com o trabalho científico dos alunos das Faculdades Integradas Campos Salles.

Desde já agradecemos a sua atenção e colaboração.

\begin{tabular}{|l|l|}
\hline 1 - Simpatia e Cordialidade no Atendimento. & 2-Capacidade de identificar a sua necessidade. \\
(1) - Muito abaixo da expectativa; & (1) - Muito abaixo da expectativa; \\
(2) - Abaixo da expectativa; & (2) - Abaixo da expectativa; \\
(3) - Conforme esperado; & (3) - Conforme esperado; \\
(4) - Mais do que esperado; & (4) - Mais do que esperado; \\
(5) - Muito mais do que esperado. & (5) - Muito mais do que esperado. \\
\hline
\end{tabular}

\begin{tabular}{|l|l|}
\hline 3 - Rapidez na apresentação do produto. & 4 - Qualidade dos serviços. \\
(1) - Muito abaixo da expectativa; & (1) - Muito abaixo da expectativa; \\
(2) - Abaixo da expectativa; & (2) - Abaixo da expectativa; \\
(3) - Conforme esperado; & (3) - Conforme esperado; \\
(4) - Mais do que esperado; & (4) - Mais do que esperado; \\
\hline
\end{tabular}




\begin{tabular}{|c|c|}
\hline (5) - Muito mais do que esperado. & (5) - Muito mais do que esperado. \\
\hline $\begin{array}{l}5 \text { - Considera-se satisfeito com o atendimento } \\
\text { realizado. } \\
\text { (1) - Muito abaixo da expectativa; } \\
\text { (2) - Abaixo da expectativa; } \\
\text { (3) - Conforme esperado; } \\
\text { (4) - Mais do que esperado; } \\
\text { (5) - Muito mais do que esperado. }\end{array}$ & $\begin{array}{l}\text { 6- Você recomendaria essa loja para amigos e/ou } \\
\text { conhecidos? } \\
\text { (1) - Sim; } \\
\text { (2) - Não. }\end{array}$ \\
\hline
\end{tabular}

